\title{
Spinal Neurons that Possess the Substance P Receptor Are Required for the Development of Central Sensitization
}

\author{
Sergey G. Khasabov, ${ }^{1,2}$ Scott D. Rogers, ${ }^{1}$ Joseph R. Ghilardi, ${ }^{1}$ Christopher M. Peters, ${ }^{1}$ Patrick W. Mantyh, ${ }^{1,3,4}$ \\ and Donald A. Simone $2,3,4$ \\ Departments of ${ }^{1}$ Preventive Sciences, ${ }^{2}$ Oral Science, ${ }^{3}$ Psychiatry, and ${ }^{4}$ Neuroscience, University of Minnesota, \\ Minneapolis, Minnesota 55455
}

In previous studies, we have shown that loss of spinal neurons that possess the substance $P$ receptor (SPR) attenuated pain and hyperalgesia produced by capsaicin, inflammation, and nerve injury. To determine the role of SPR-expressing neurons in modulating pain and hyperalgesia, responses of superficial and deep lumbar spinal dorsal horn neurons evoked by mechanical and heat stimuli and by capsaicin were made after ablation of SPR-expressing neurons using the selective cytotoxin conjugate substance P-saporin (SP-SAP). Morphological analysis and electrophysiological recordings were made after intrathecal infusion of vehicle, saporin alone, or SP-SAP. SPSAP, but not vehicle or SAP alone, produced an $\sim 62 \%$ decrease in SPR-expressing neurons in the dorsal horn. Loss of SPR-expressing neurons diminished the responses of remaining neurons to intraplantar injection of capsaicin. Peak re-

Chronic pain and hyperalgesia are symptoms associated with tissue injury and inflammation. The neural mechanisms underlying persistent pain and hyperalgesia are not fully understood but are known to involve sensitization of primary afferent nociceptors and central sensitization. Previous studies have shown that excitability of nociceptive dorsal horn neurons is enhanced after tissue injury, and responses evoked by both innocuous and noxious stimuli are increased after injury and are believed to contribute to allodynia and hyperalgesia (Treede et al., 1992; Millan, 1999; Mannion and Woolf, 2000).

It is well established that substance P (SP) participates in nociceptive transmission in the spinal cord. SP is synthesized in small-caliber afferent fibers (McCarthy and Lawson, 1989) and released into the spinal cord after noxious stimulation (Duggan et al., 1987; Schaible et al., 1990), excites nociceptive dorsal horn neurons (Radhakrishnan and Henry, 1991), and contributes to the development of hyperalgesia (Moochhala and Sawynok, 1984). When released into the spinal cord, SP interacts with the substance P receptor (SPR), also referred to as the neurokinin-1 (NK-1) receptor, to produce its postsynaptic effects. Although $<10 \%$ of lamina I neurons possess the SPR (Brown et al., 1995; Littlewood et al., 1995), the majority belong to the spinothalamic tract (STT) and spinoparabrachial tract and are involved in the ascending transmission of nociceptive information. We have dem-

Received May 20, 2002; revised July 29, 2002; accepted Aug. 5, 2002.

This work was supported by National Institutes of Health Grant DA11986. Saporin and SP-SAP were obtained from Advanced Targeting Systems.

Correspondence should be addressed to Dr. Donald A. Simone, Department of Oral Science, University of Minnesota, 515 Delaware Street Southeast, 17-252 Moos, Minneapolis, MN 55455. E-mail: simon003@umn.edu.

Copyright () 2002 Society for Neuroscience 0270-6474/02/229086-13\$15.00/0 sponses to $10 \mu \mathrm{g}$ of capsaicin were $\sim 65 \%$ lower in animals pretreated with SP-SAP compared with controls. Additionally, sensitization to mechanical and heat stimuli that normally follows capsaicin was rarely observed. Importantly, responses to mechanical and heat stimuli in the absence of capsaicin were not altered after SP-SAP treatment. In addition, nociceptive neurons did not exhibit windup in the SP-SAP-treated group. These results demonstrate that SPR-expressing neurons located in the dorsal horn are a pivotal component of the spinal circuits involved in triggering central sensitization and hyperalgesia. It appears that this relatively small population of neurons can regulate the physiological properties of other nociceptive neurons and drive central sensitization.

Key words: hyperalgesia; capsaicin; electrophysiology; spinal cord; substance P-saporin; windup

onstrated that SPR-expressing neurons have a unique role in processing nociceptive information, and their intact function may be critical for the development of chronic pain and hyperalgesia. Using internalization of the SPR as a portal of entry to the cell, intrathecal application of a conjugate of SP and the ribosomeinactivating toxin saporin (SP-SAP) resulted in a dramatic loss of lamina I SPR-expressing neurons and attenuated the nocifensive behavior and hyperalgesia produced by capsaicin (Mantyh et al., 1997), inflammation, and nerve injury (Nichols et al., 1999). Importantly, basal pain reactivity was not affected. Although these studies showed that SPR-expressing neurons are necessary for the development of hyperalgesia, the exact role of these neurons in pain processing is unclear. One possibility is that these are the neurons excited by and sensitized after injury or inflammation. This is supported by studies demonstrating that STT neurons, including those located in lamina I, become sensitized after injury and contribute to hyperalgesia (Simone et al., 1991). To determine further the role of SPR-containing neurons in nociceptive transmission, we examined the response properties and sensitization of superficial and deep dorsal horn neurons in rats pretreated intrathecally with SP-SAP. Our results suggest that SPR-possessing neurons in the dorsal horn are an integral component of a spinal and/or supraspinal circuit that is crucial for the development of central sensitization after capsaicin.

\section{MATERIALS AND METHODS}

Subjects

Seventy-two adult male Sprague Dawley rats (Harlan Industries, Indianapolis, IN) weighing 290-470 gm have been housed and used under approval of the Animal Care Committee at the University of Minnesota. 
Experiments were conducted according to the guidelines set forth by the International Association for the Study of Pain.

\section{Intrathecal injection}

Rats were anesthetized by intramuscular injection of ketamine (100 $\mathrm{mg} / \mathrm{kg}$ ) and acepromazine $(45 \mathrm{mg} / \mathrm{kg}$ ) and were placed into a stereotaxic frame. An incision was made in the atlanto-occipital membrane, and a polyethylene catheter (Intramedic, Sparks, MD) (inner diameter, 0.28 $\mathrm{mm}$; outer diameter, $0.61 \mathrm{~mm}$ ) was inserted into the intrathecal space to the area of lumbar enlargement. Animals were given one intrathecal injection of normal saline $(n=27), 5 \times 10^{-5}$ M saporin $(n=12)$, or $5 \times$ $10^{-5}$ M SP-SAP $(n=33)$. All injections were given in a volume of $10 \mu \mathrm{l}$ followed by a $5 \mu \mathrm{l}$ flush with saline. After injection, the catheter was removed, and the incision was closed by suture. Experiments were performed 10 or $30 \mathrm{~d}$ after injection.

\section{Immunohistochemistry and quantification}

Animals pretreated with an intrathecal injection of saline vehicle, SAP, or SP-SAP ( $n=5$ per group) were deeply anesthetized with sodium pentobarbital $(50 \mathrm{mg} / \mathrm{kg}$, i.p.) and perfused intracardially with $12 \mathrm{ml}$ of $0.1 \mathrm{~m}$ PBS followed by $25 \mathrm{ml}$ of $4 \%$ formaldehyde in $0.1 \mathrm{M}$ PBS. Spinal cord segments L1-S2 were removed, postfixed for $16 \mathrm{hr}$ in the perfusion fixative, and cryoprotected for $24 \mathrm{hr}$ in $30 \%$ sucrose in $0.1 \mathrm{M}$ PBS. Serial frozen spinal cord sections, $60 \mu \mathrm{m}$ thick, were cut on a sliding microtome, collected in PBS, and processed as free-floating sections. Tissue sections were incubated for $30 \mathrm{~min}$ at room temperature in a blocking solution of
$1 \%$ normal donkey or goat serum in PBS with $0.3 \%$ Triton X-100 and then incubated overnight at room temperature in the primary antiserum for the substance P receptor (rabbit anti-SPR, 1:5000; raised in our laboratory). After incubation, tissue sections were washed three times for $10 \mathrm{~min}$ in PBS and incubated in the secondary antibody solution for $2 \mathrm{hr}$ at room temperature. Secondary antibodies conjugated to the fluorescent marker Cy3 (Jackson ImmunoResearch, West Grove, PA) were used at 1:600. Finally, the sections were washed three times for $10 \mathrm{~min}$ in PBS, mounted on gelatin-coated slides, air dried, dehydrated via an alcohol gradient $(70,90$, and $100 \%)$, cleared in xylene, and coverslipped. To confirm the specificity of the primary antibody, controls included preabsorption with the corresponding synthetic peptide or omission of the primary antibody.

Slides were viewed through a $1 \mathrm{~cm}^{2}$ eyepiece grid, which was divided into $1001 \times 1 \mathrm{~mm}$ units, and the total number of immunofluorescent cell bodies per unit area was counted. The mean numbers of SPRimmunoreactive (SPR-IR) cell bodies located in the superficial (laminas I and II) and deep (laminas III-V) dorsal horn were obtained from three to eight sections per animal.

\section{Electrophysiological recordings}

Rats were anesthetized by intramuscular injection of ketamine (100 $\mathrm{mg} / \mathrm{kg}$ ) and acepromazine $(45 \mathrm{mg} / \mathrm{kg})$. The trachea was cannulated to provide unobstructed ventilation, and a catheter was inserted into the external jugular vein for supplemental anesthesia with sodium pentobarbital $\left(10 \mathrm{mg} \cdot \mathrm{kg}^{-1} \cdot \mathrm{hr}^{-1}\right)$. Areflexia was maintained by monitoring the
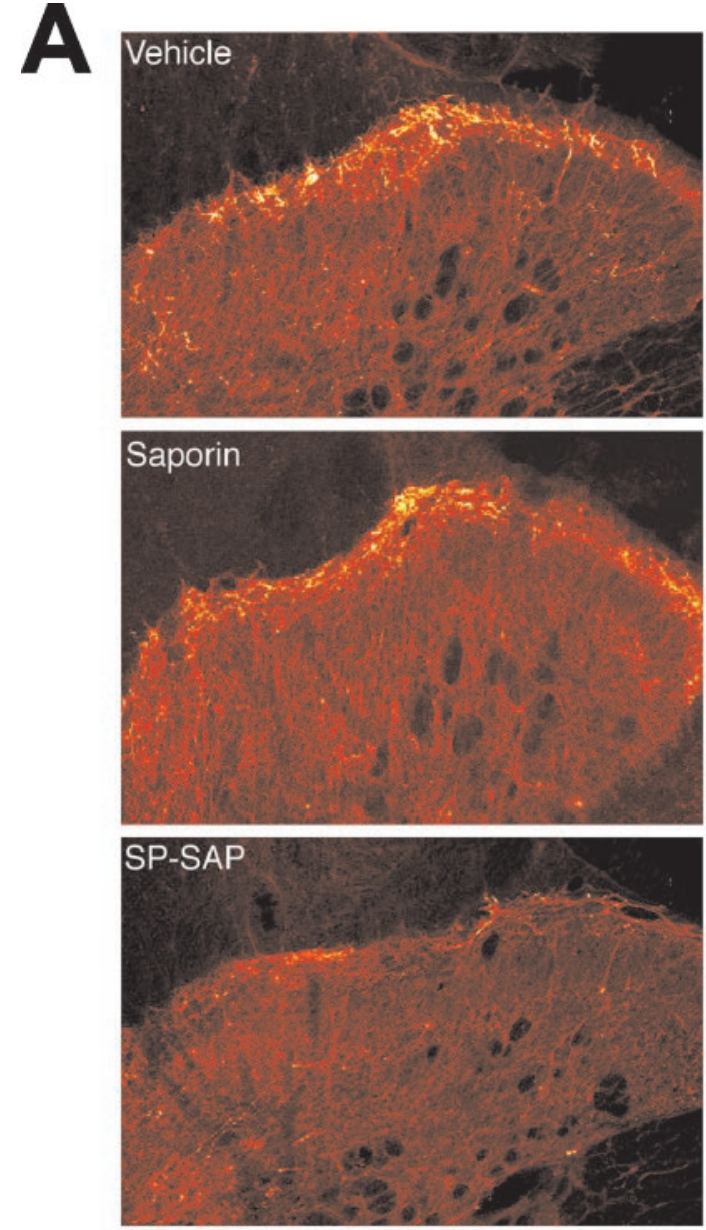

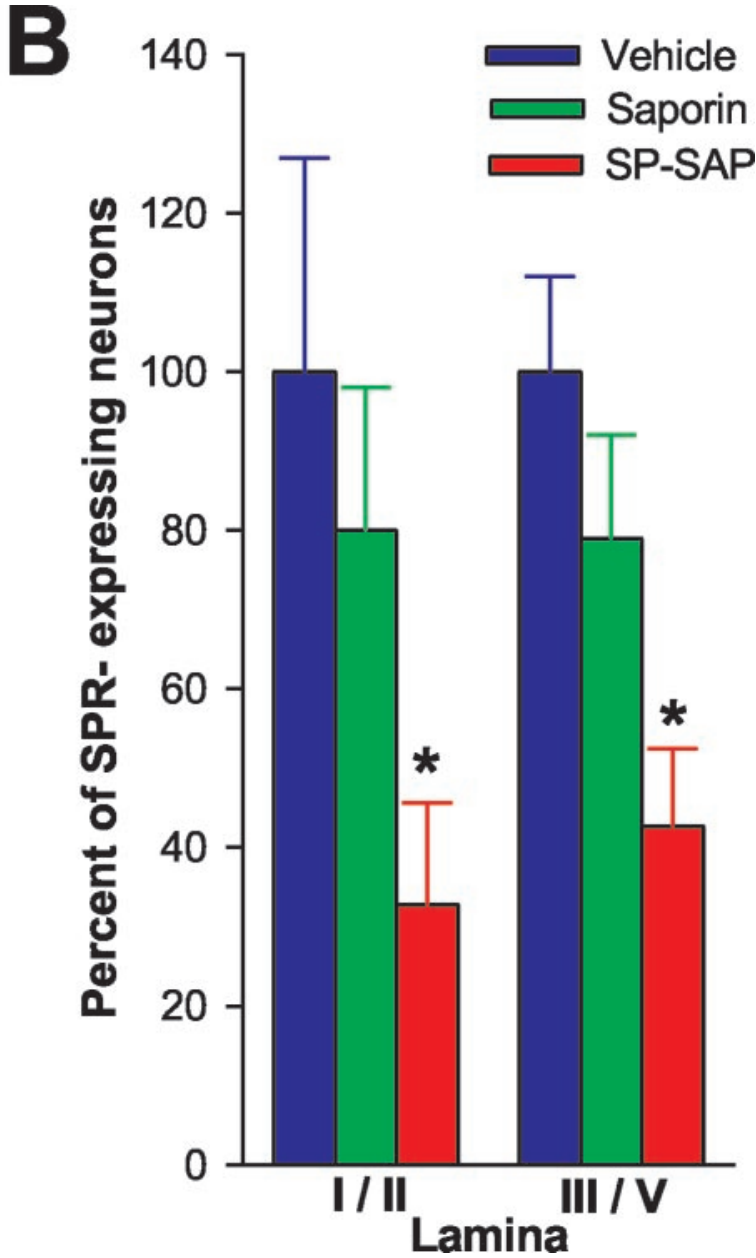

Figure 1. Loss of SPR-expressing neurons after intrathecal infusion of SP-SAP. $A$, Confocal images showing representative examples of SPR-IR in animals pretreated intrathecally with vehicle, SAP alone, or SP-SAP. A dramatic reduction in SPR-IR is evident after SP-SAP. $B$, Mean \pm SEM percentage of neurons that express the SPR after intrathecal vehicle, SAP, or SP-SAP. The number of SPR-expressing cells was obtained from individual animals, and a mean \pm SEM was calculated. This mean value was designated as $100 \%$, and the SEM was proportionately adjusted (as a percentage) to provide a measure of variability. Data for SAP- and SP-SAP-treated groups represent the percentage of cells compared with the vehicle-treated group. $*$ Significant differences from vehicle. 


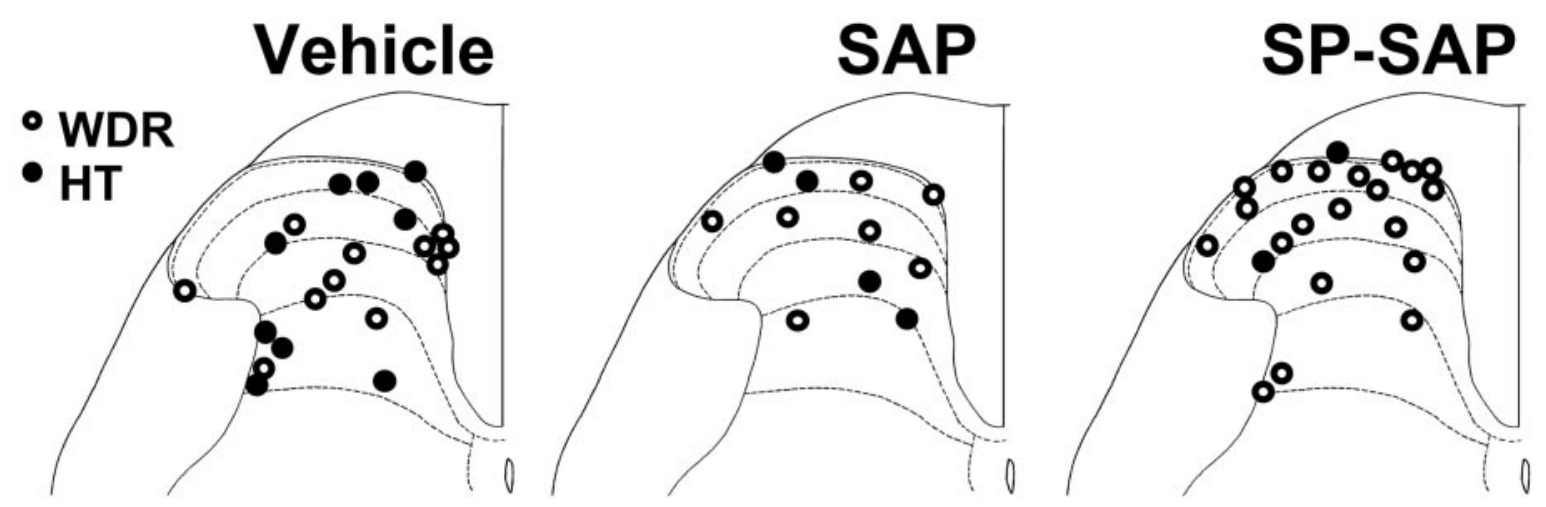

Figure 2. Location of recording sites for all dorsal horn neurons. Neurons studied in rats pretreated with vehicle, SAP, and SP-SAP were distributed in the superficial and deep dorsal horn in all groups.

Table 1. General response properties of nociceptive neurons follow intrathecal injection of vehicle, SAP, or SP-SAP

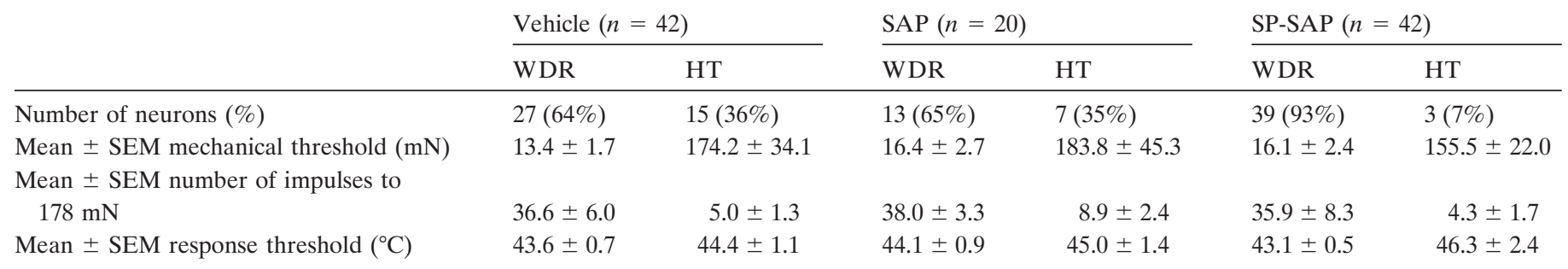

corneal reflex at frequent intervals throughout the experiment. The carotid artery was cannulated, and mean blood pressure was monitored continuously with a pressure transducer (World Precision Instruments, Sarasota, FL). Experiments were terminated if mean pressure dropped below $60 \mathrm{mmHg}$. The lumbar enlargement was exposed by laminectomy, and the animal was secured in a spinal frame. The spinal cord was continually bathed in a pool of warm $\left(37^{\circ} \mathrm{C}\right)$ mineral oil. Core body temperature was maintained at $37^{\circ} \mathrm{C}$ by a feedback-controlled heating pad.

Extracellular recordings of single dorsal horn neurons with receptive fields (RFs) located on the plantar surface of the hindpaw were obtained using stainless steel microelectrodes (Frederick Haer and Co., Brunswick, ME) $(10 \mathrm{~m} \Omega)$. Recording electrodes were lowered into the spinal cord at the L4 and L5 segments using an electronic micromanipulator (Burleigh Instruments, Fishers, NY) in $5 \mu \mathrm{m}$ steps. Recordings were made only from single neurons whose amplitude could be easily discriminated. Electrophysiological activity was amplified using an alternating current amplifier (model DAM80; World Precision Instruments), audio monitored (Grass AM8 audiomonitor; Grass Instruments, West Warwick, RI), and displayed on a storage oscilloscope before being sent to a computer for data collection using a customized version of Lab View (National Instruments, Austin, TX) software that enabled storage of raw data, discriminated impulses, and stimulus temperature. In most experiments, recordings were obtained from two neurons, one on each side of the spinal cord.

Functional classification of spinal neurons. Search stimuli consisted of mechanical stimulation (stroking the skin and mild pinching with the experimenter's fingers) of the rat hindpaw. The RFs of isolated neurons were mapped with a suprathreshold von Frey monofilament. Each spinal neuron was characterized based on its response to graded intensities of mechanical stimulation applied to the RF. Innocuous stimuli consisted of stroking the skin with a cotton swab. Noxious stimulation included mild pinching with the experimenter's fingers and with serrated forceps, but this latter stimulus was applied sparingly to avoid neuronal sensitization. Neurons were classed functionally according to responses evoked by mechanical stimuli as: (1) low threshold if they were excited maximally by innocuous stimulation, (2) wide dynamic range (WDR) if they responded in a graded manner to increasing intensity of stimulation, and (3) high threshold (HT) if responses were evoked by noxious stimulation only. Only WDR and HT neurons were studied.

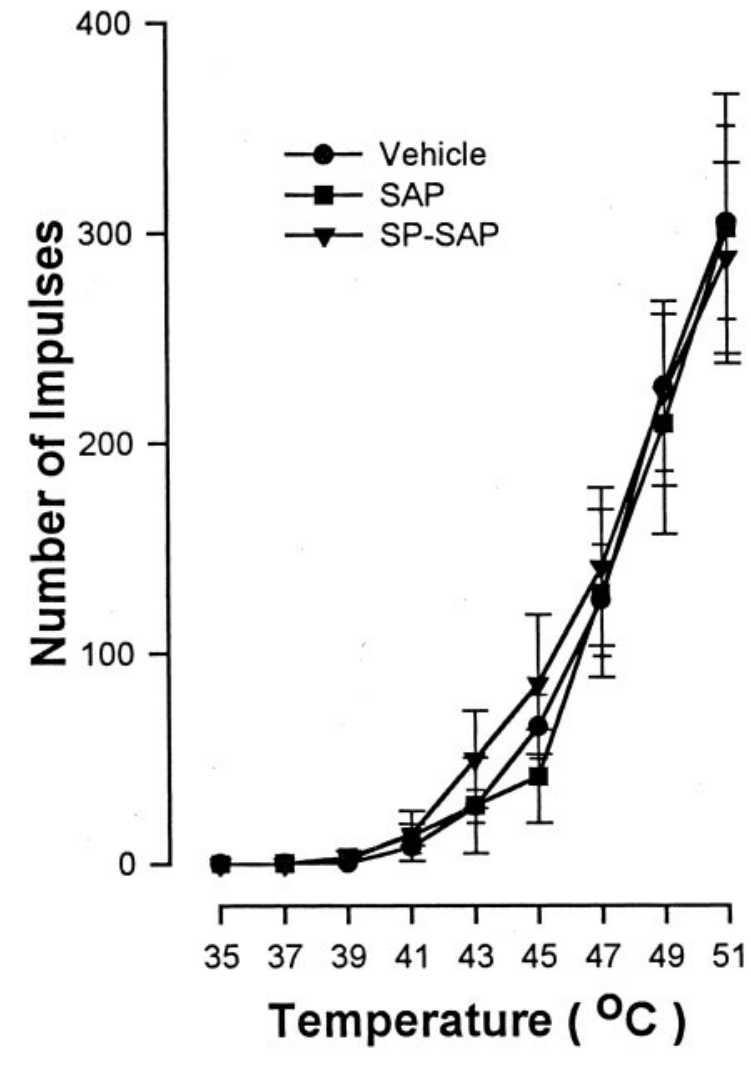

Figure 3. The mean \pm SEM number of impulses evoked by heat after pretreatment with vehicle, SAP, and SP-SAP. Responses evoked by heat stimuli of $35-51^{\circ} \mathrm{C}$ did not differ between groups before capsaicin injection. 


\section{A}
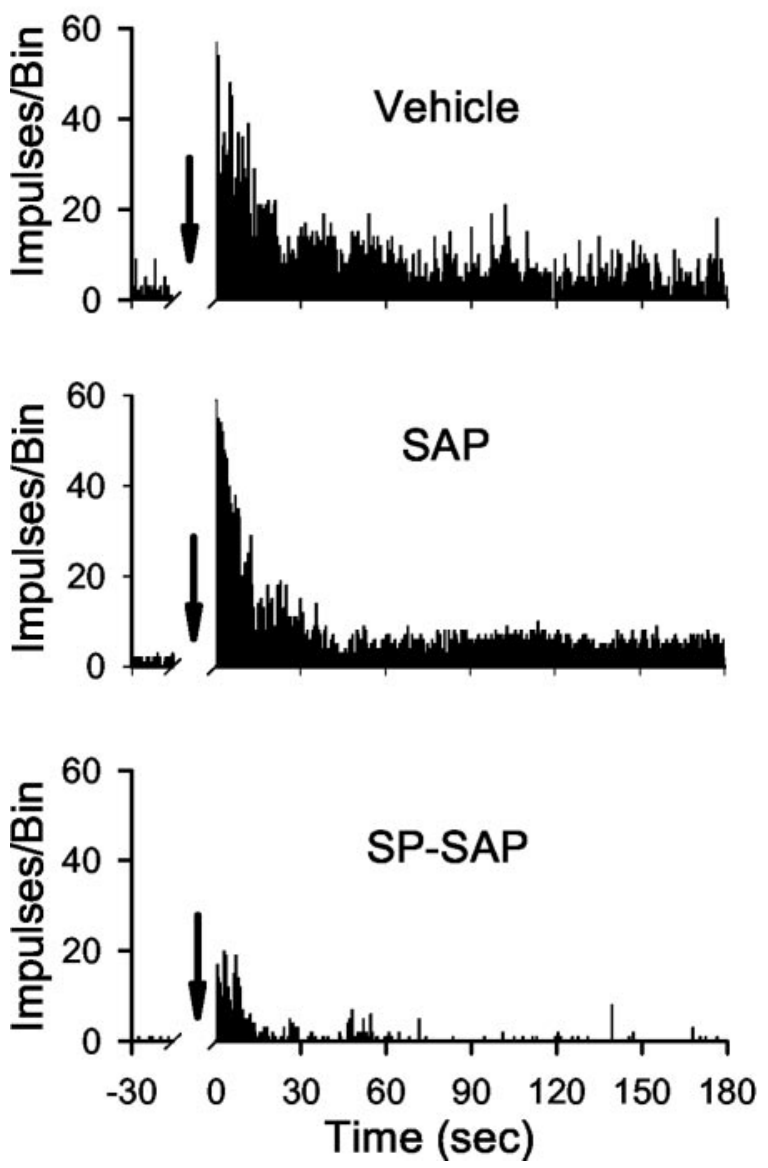

B

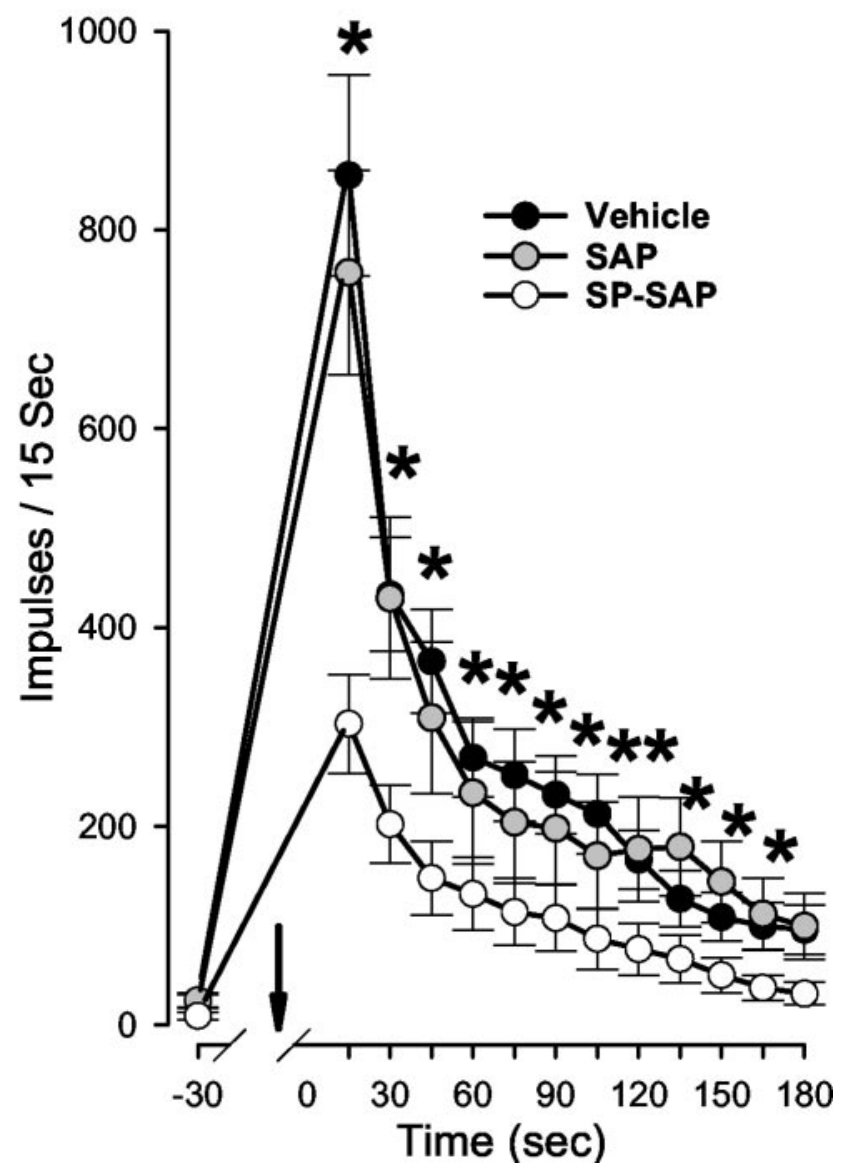

Figure 4. Responses evoked by $10 \mu \mathrm{g}$ of capsaicin are diminished in animals pretreated with SP-SAP. $A$, Responses of single WDR neurons to intradermal injection of capsaicin from vehicle-, SAP-, and SP-SAP-treated rats. Bin size is 500 msec. $B$, Mean \pm SEM number of impulses per 15 sec interval after capsaicin. Arrows indicate the time of injection. *Significant difference between vehicle and SP-SAP groups. Responses to capsaicin were weaker in animals that received SP-SAP compared with those that received vehicle or SAP alone.

Evoked response measures and experimental design. After identification and general functional characterization of a neuron as WDR or HT, the RF was mapped by stroking and mildly pinching with forceps and outlined on the skin with a felt-tip pen. Mechanical threshold (in milliNewtons) was determined using calibrated von Frey monofilaments applied to the most sensitive area of the RF. To obtain responses evoked by mechanical stimuli before and after capsaicin, four test sites within the RF were marked on the skin and stimulated with a von Frey monofilament $(178 \mathrm{mN}$ bending force applied for $2 \mathrm{sec})$. Each test site was stimulated three times with a $10 \mathrm{sec}$ interval between stimuli. To determine response evoked by heat, stimuli of $35-51^{\circ} \mathrm{C}$ were applied in ascending order of $2^{\circ} \mathrm{C}$ increments from a base temperature of $32^{\circ} \mathrm{C}$ using a Peltier thermode (contact area of $1 \mathrm{~cm}^{2}$ ). Stimuli were of $5 \mathrm{sec}$ duration and were delivered at a ramp rate of $18^{\circ} \mathrm{C} / \mathrm{sec}$ with an interstimulus interval of $60 \mathrm{sec}$. Capsaicin (10 or $100 \mu \mathrm{g}$ in $10 \mu \mathrm{l}$ ) was injected intradermally into the middle of the RF. Responses evoked by capsaicin were recorded for $5 \mathrm{~min}$, and responses evoked by mechanical and heat stimuli were again determined as described above. At the end of the experiment, the recording site was marked by passing current $(10 \mu \mathrm{A}$ for $20 \mathrm{sec}$ ) through the recording electrode.

In separate experiments, we determined whether nociceptive neurons in vehicle-treated animals $(n=8)$ and SP-SAP-treated animals $(n=8)$ exhibited windup. Neurons were activated by 12 successive electrical stimuli applied to the RF via fine needle electrodes. Stimuli of $1 \mathrm{msec}$ duration were applied at the rate of $0.5 \mathrm{~Hz}$ and at a current intensity that was $150 \%$ of threshold intensity that produced a long latency $(110-450$ $\mathrm{msec}) \mathrm{C}$-fiber-evoked response.

Histological localization of recording sites. Animals were perfused with normal saline followed by $10 \%$ formalin containing $1 \%$ potassium ferrocyanide. Serial transverse sections $(50 \mu \mathrm{m})$ were cut using a vibratome and stained with neutral red. Recording sites were identified by Prussian Blue marks or small lesions.

\section{Data analyses}

The numbers of SPR-IR cell bodies, impulses evoked by capsaicin, and impulses evoked by mechanical and heat stimuli before and after capsaicin were compared between groups using ANOVA and Bonferroni post hoc comparisons. Evoked responses were determined by subtracting the spontaneous discharge rate from the response that occurred during the stimulus. The proportion of neurons that were classed as HT and WDR neurons was compared between the groups using the $\chi^{2}$ test. The number of SPR-expressing neurons after SAP and SP-SAP was normalized to the number of neurons found in vehicle-treated animals. For all statistical tests, a $p$ value of $<0.05$ was considered significant.

\section{RESULTS}

\section{Ablation of SPR-expressing neurons after intrathecal SP-SAP: morphological characteristics}

In animals pretreated with vehicle or SAP, SPR immunoreactivity is observed on cell bodies and dendrites located primarily in lamina I; however, distinct SPR immunoreactivity was also found on neurons located in the deep dorsal horn. No differences occurred in the number of SPR-expressing neurons in animals 

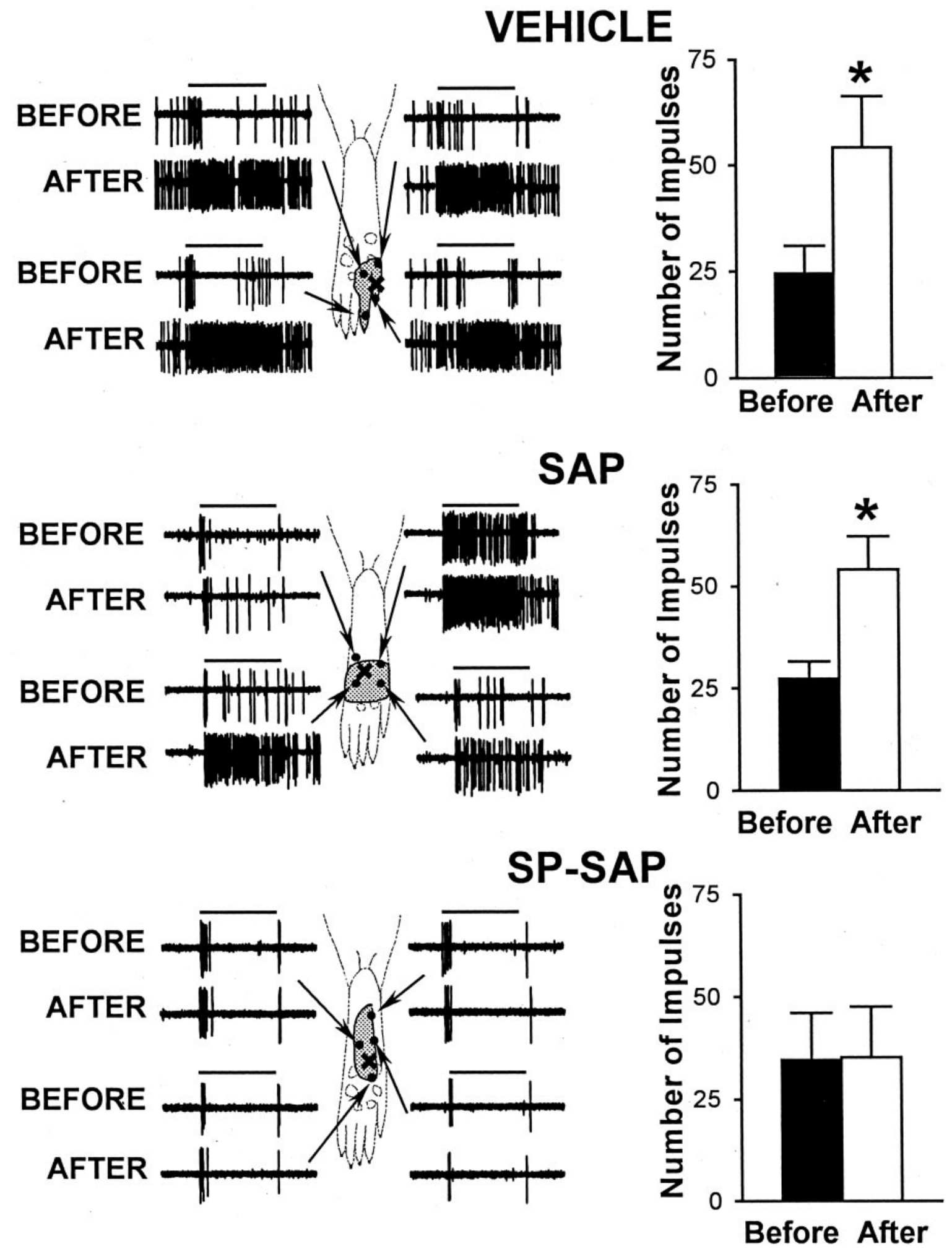

Figure 5. Sensitization of nociceptive neurons to mechanical stimuli (178 mN bending force) after $10 \mu \mathrm{g}$ of capsaicin does not occur in animals pretreated with SP-SAP. Left panels, Representative examples illustrating responses of WDR neurons to mechanical stimuli before and after capsaicin in vehicle-, SAP-, and SP-SAP-treated groups. RFs are indicated by the stippled area, and test sites for mechanical stimulation are indicted by the dots within the RF. Arrows point to specific test sites at which pairs of responses (before and after capsaicin) were obtained. The capsaicin injection is indicated by the $\times$. Horizontal bars denote time of stimulation $(2 \mathrm{sec})$. Right panels, Mean \pm SEM number of impulses evoked by a single mechanical stimulus before and after capsaicin in animals pretreated with vehicle, SAP, or SP-SAP. *Significant difference after capsaicin compared with before capsaicin. 
A

BEFORE CAPSAICIN
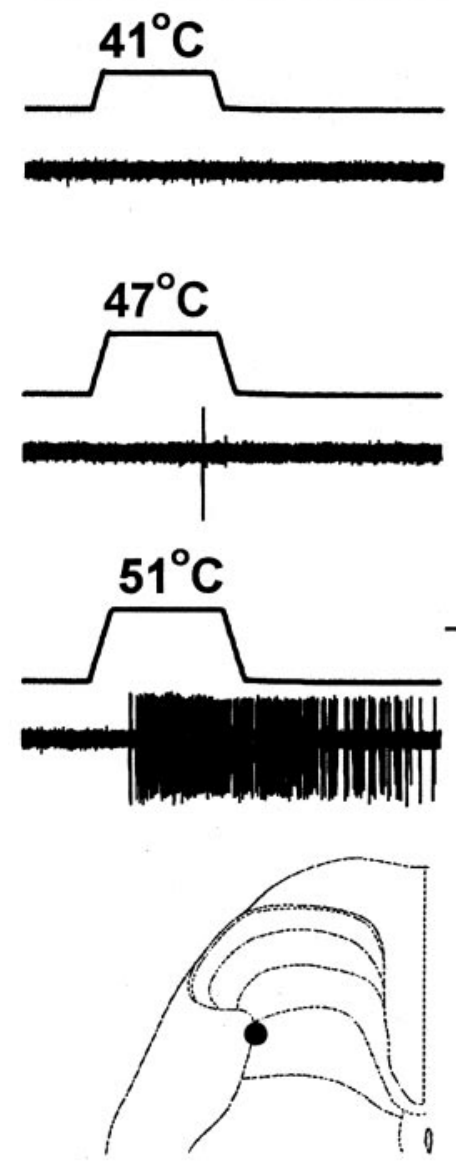

AFTER CAPSAICIN
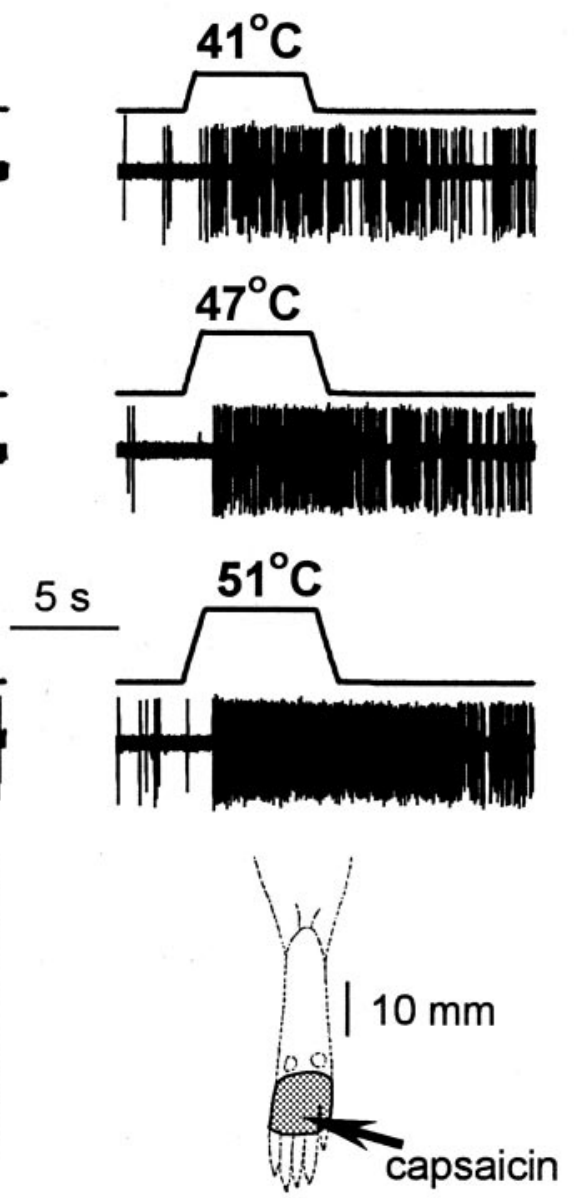

B
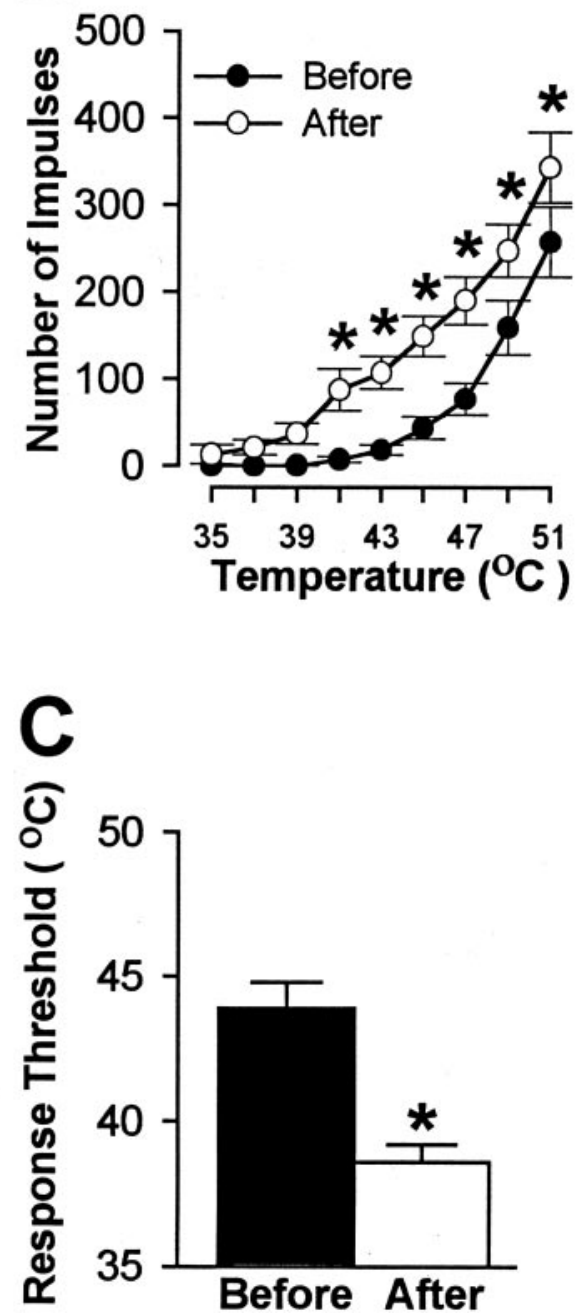

Figure 6. Sensitization to heat produced by $10 \mu \mathrm{g}$ of capsaicin in animals pretreated with intrathecal infusion of vehicle. $A$, Responses of an HT neuron to heat stimuli of 41,47 , and $51^{\circ} \mathrm{C}$ before and after capsaicin. Also shown is the localization of the recording site for these neurons and its RF (stippled area). The arrow points to location of capsaicin injection. $B$, Mean \pm SEM number of impulses evoked by heat stimuli before and after capsaicin for all neurons. Mean responses to heat increased after capsaicin. $C$, Mean \pm SEM heat threshold for all neurons before and after capsaicin. Response threshold decreased after capsaicin. *Significant difference between mean values obtained before and after capsaicin.

pretreated with vehicle or with SAP alone (Fig. 1). Animals pretreated with SAP alone exhibited $80 \pm 16 \%$ and $79 \pm 13 \%$ of SPR-IR neurons in lamina I/II and laminas III-V, respectively, compared with animals pretreated with vehicle. In contrast, a significant reduction in the number of SPR-IR neurons was observed in animals pretreated with SP-SAP. These animals exhibited only $32 \pm 13 \%$ and $42 \pm 9.9 \%$ of SPR-IR neurons in lamina $\mathrm{I} / \mathrm{II}$ and in laminas III-V, respectively, compared with the vehicletreated group. Thus, animals pretreated with SP-SAP exhibited a decrease in SPR-expressing neurons in the superficial and deep dorsal horn of 65 and $58 \%$, respectively.

\section{Ablation of SPR-expressing neurons after intrathecal SP-SAP: electrophysiological responses \\ General response properties}

Seventy-two rats were pretreated intrathecally with saline (vehicle; $n=27)$, SAP alone $(n=12)$, or SP-SAP $(n=33)$. Electrophysiological responses were obtained from a total of 104 nociceptive dorsal horn neurons. Forty-two cells (27 WDR and 15
HT) were studied in animals pretreated with vehicle, 20 cells (13 WDR and 7 HT) were studied in animals pretreated with SAP, and 42 cells (39 WDR and 3 HT) were studied after SP-SAP treatment. Within each group, no differences were observed in responses of neurons studied 10 or $30 \mathrm{~d}$ after treatment, and data from these time points were therefore combined. Receptive fields of all neurons included the plantar surface of the hindpaw. Recording sites were recovered for 53 neurons and were found to be located in the superficial and deep dorsal horn. Recording sites of WDR and HT neurons in vehicle-, SAP-, and SP-SAP-treated groups are illustrated in Figure 2, which shows that recording sites were distributed throughout the dorsal horn in all treatment groups. Similarly, the mean recording depth from the spinal cord surface for all neurons did not differ between groups and was $547 \pm 63,502 \pm 77$, and $438 \pm 44 \mu \mathrm{m}$ for the vehicle, SAP, and SP-SAP groups, respectively.

The proportion of WDR and HT neurons studied in each treatment group, as well as their general response characteristics 
A
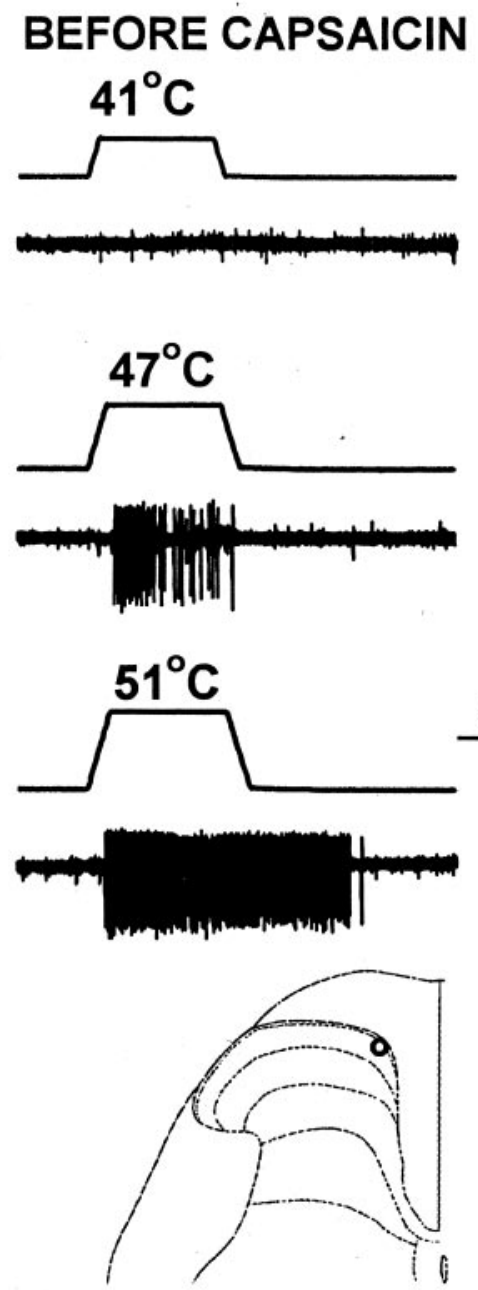

AFTER CAPSAICIN
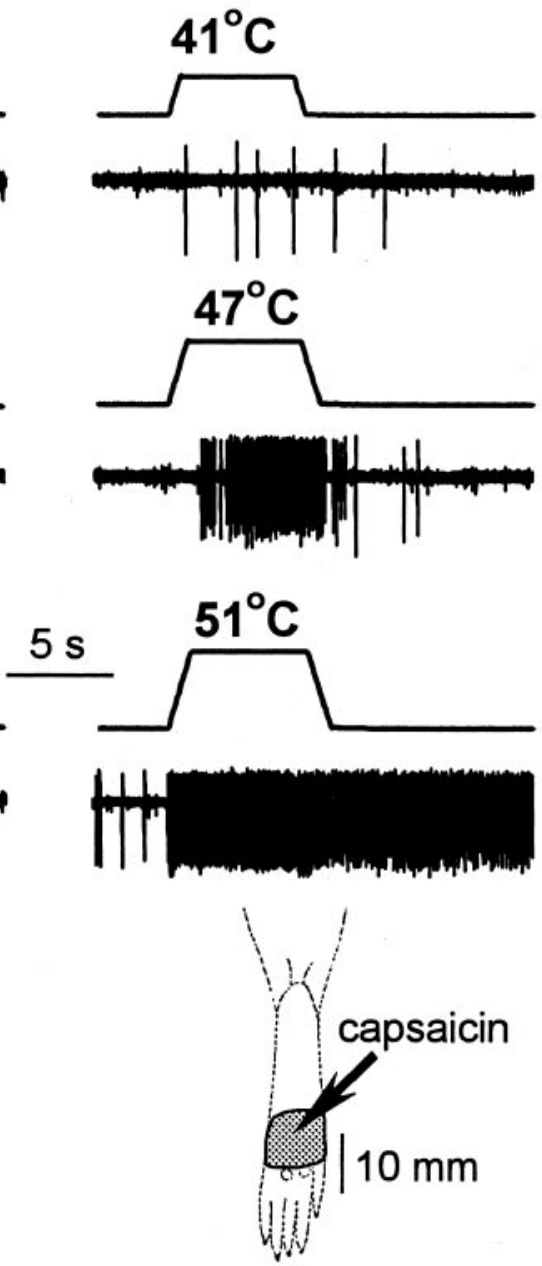
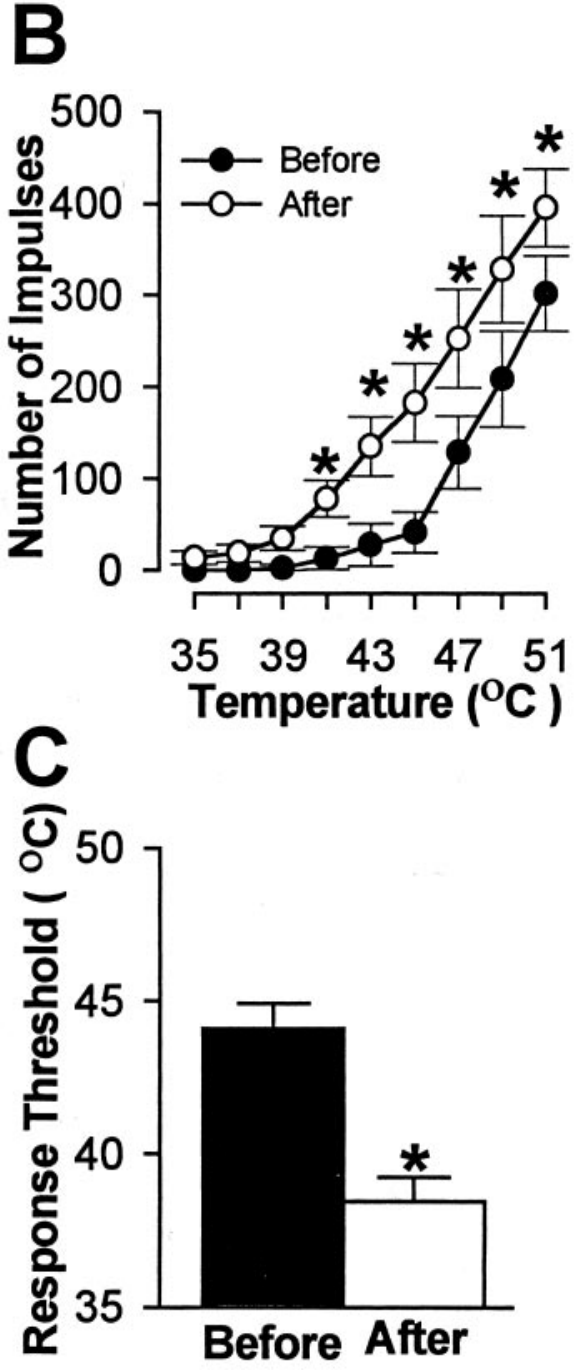

Figure 7. Sensitization to heat in SAP-treated animals after $10 \mu \mathrm{g}$ of capsaicin. $A$, Responses of a WDR neuron to heat stimuli before and after capsaicin. Also shown are the recording site and the RF (stippled area) for this neuron. The arrow points to location of capsaicin injection. $B$, Mean \pm SEM number of impulses evoked by heat stimuli before and after capsaicin for all neurons. Responses to heat increased after capsaicin. $C$, Mean \pm SEM heat threshold for all neurons before and after capsaicin. Response threshold decreased after capsaicin. *Significant difference after capsaicin.

(mean mechanical threshold, mean number of impulses evoked by a suprathreshold von Frey monofilament with a bending force of $178 \mathrm{mN}$ applied for $2 \mathrm{sec}$, and mean heat threshold) before capsaicin injection, are provided in Table 1. Responses of WDR and HT neurons showed quantitative differences in their responses to mechanical stimuli in that HT neurons exhibited a higher response threshold and were less responsive to the suprathreshold von Frey monofilament. However, responses of WDR and HT neurons to mechanical stimuli before capsaicin did not differ between treatment groups. Additionally, no differences were found between WDR and HT neurons in their responses to heat before capsaicin. As shown in Figure 3, mean response functions of nociceptive neurons for heat stimuli of $35-51^{\circ} \mathrm{C}$ before capsaicin did not differ between groups. The mean cumulative numbers of impulses evoked across all heat stimuli were $759.3 \pm 124.1,726.9 \pm 179.7$, and $805.5 \pm 172.1$ after vehicle, SAP, and SP-SAP, respectively.

Although the response properties of nociceptive neurons did not differ among the groups, a difference was found in the pro- portion of WDR and HT neurons encountered between groups. Neurons classed as HT were 36 and $35 \%$ in vehicle- and SAPtreated animals, respectively, whereas the number of HT neurons encountered in SP-SAP-treated animals was significantly lower. Only three neurons $(7 \%)$ in SP-SAP-treated rats were classed as HT $(p<0.003)$ (Table 1).

\section{Responses to capsaicin and central sensitization}

Responses evoked by intraplantar capsaicin injections were decreased in animals pretreated with SP-SAP. Injection of $10 \mu \mathrm{g}$ of capsaicin (in $10 \mu \mathrm{l}$ ) produced a vigorous and long-lasting discharge in all WDR and HT neurons recorded from animals pretreated with vehicle $(n=34)$ or SAP alone $(n=20)$. Discharge rates were highest soon after injection, decreased to a moderate level within $\sim 1$ min after injection, and typically persisted for $>3$ min (Fig. 4A). Responses of WDR and HT neurons were similar and did not differ between vehicle- and SAP-treated groups. In contrast, capsaicin-evoked responses of WDR and HT neurons $(n=29)$ were much weaker in animals pretreated with 
A

BEFORE CAPSAICIN
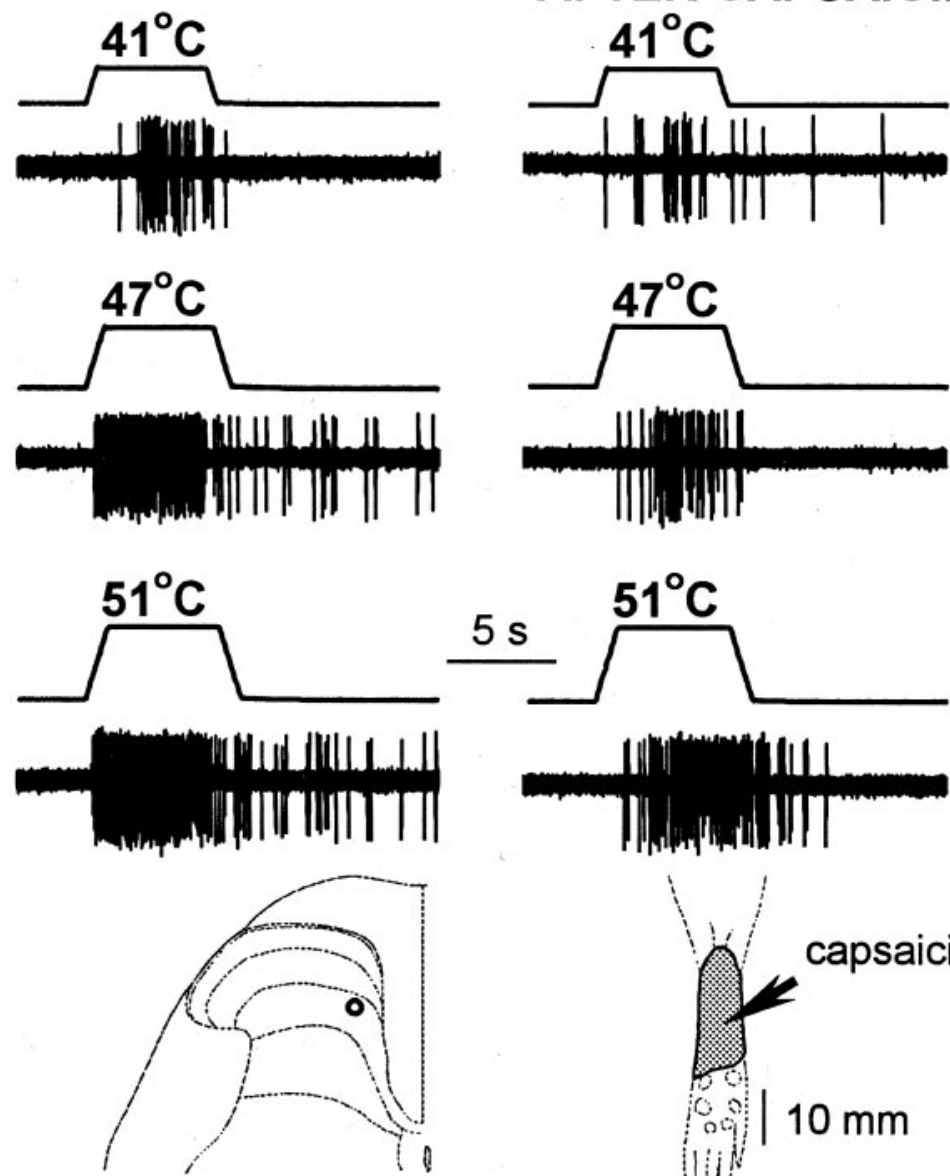

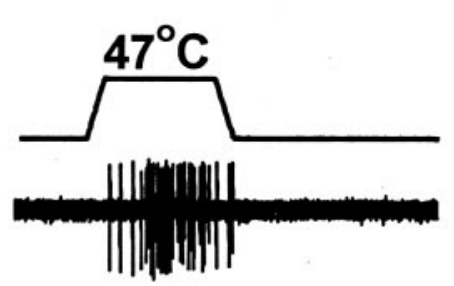

AFTER CAPSAICIN
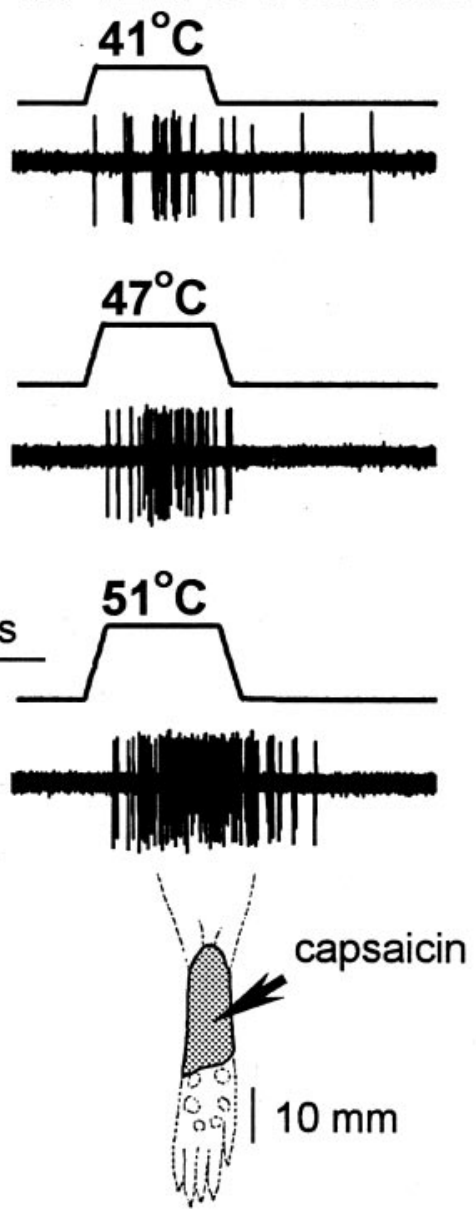

B

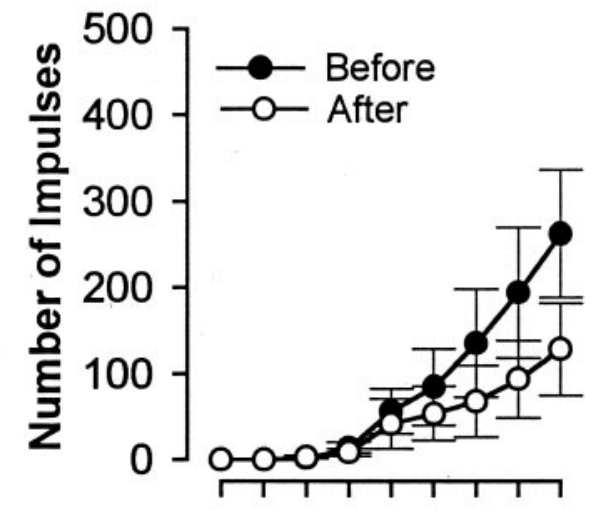

$\begin{array}{lllll}35 & 39 & 43 & 47 & 51\end{array}$
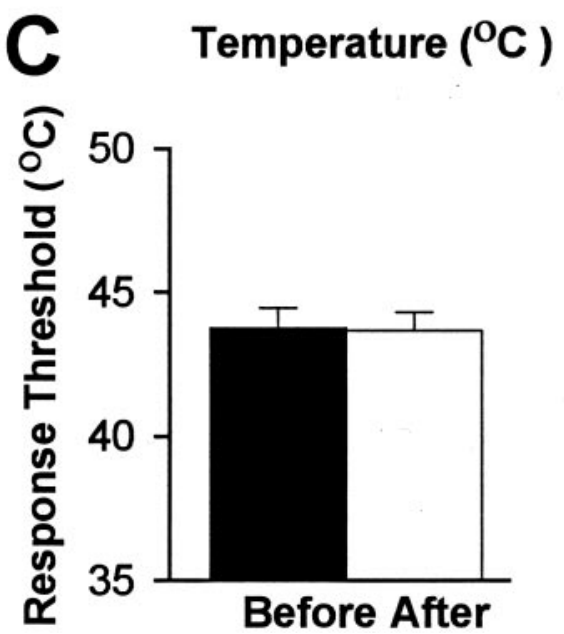

Figure 8. Lack of capsaicin-evoked sensitization to heat in animals pretreated with SP-SAP. $A$, Responses of a WDR neuron to heat stimuli before and after capsaicin. The recording site and the RF (stippled area) are shown for this neuron. The arrow points to location of capsaicin (10 $\mu \mathrm{g})$ injection. $B$, Mean \pm SEM number of impulses evoked by heat stimuli before and after capsaicin for all neurons. There was a tendency for heat-evoked responses to decrease after capsaicin. $C$, Mean \pm SEM heat threshold for all neurons before and after capsaicin.

SP-SAP, and the duration of response was often shorter. Before injection, mean discharge rates of spontaneous activity did not differ between the groups. Because no differences in responses occurred between WDR and HT neurons within each group, responses of these neurons were combined. The mean number of impulses evoked during the first $15 \mathrm{sec}$ after capsaicin was $855 \pm$ 101 and $757 \pm 102$ for the vehicle- and SAP-treated groups, respectively, but was only $303 \pm 50$ impulses in animals treated with SP-SAP $(p<0.01)$ (Fig. $4 B)$. Thus, the peak response to capsaicin was $\sim 65 \%$ less in animals pretreated with SP-SAP compared with vehicle. Although the mean number of impulses that occurred in each consecutive $15 \mathrm{sec}$ interval after capsaicin was similar for the vehicle- and SAP-treated groups, capsaicinevoked discharges were less in SP-SAP-treated rats during the entire 3 min period after capsaicin injection.

Before and at $10 \mathrm{~min}$ after injection of capsaicin, responses evoked by a suprathreshold von Frey monofilament $(178 \mathrm{mN}$ bending force) were determined at selected sites within the RF that were $\geq 2 \mathrm{~mm}$ away from the capsaicin injection. In animals pretreated with vehicle or with SAP alone, all WDR and HT neurons located in the superficial or deep dorsal horn exhibited an increase in mechanically evoked responses after capsaicin. Responses to mechanical stimuli were increased similarly throughout the RF. In vehicle-treated animals, the mean number of impulses evoked by the von Frey monofilament increased from $24.6 \pm 6.4$ to $54.2 \pm 12.1$ (or $120 \% ; p<0.001$ ) after capsaicin. A similar increase of $98 \%$ in evoked responses was found in the SAP-treated group; the mean number of impulses increased from $27.3 \pm 4.3$ to $54.2 \pm 8.2(p<0.001)$. In contrast, none of the WDR or HT neurons in SP-SAP-treated rats exhibited sensitization to mechanical stimuli after capsaicin injection (Fig. 5). The mean number of impulses evoked by the monofilament was $34.6 \pm$ 11.5 before capsaicin and $35.3 \pm 12.4$ after capsaicin.

Pretreatment with SP-SAP also prevented the sensitization to heat stimuli that normally occurs after capsaicin. Before capsaicin, heat thresholds and responses evoked by suprathreshold heat stimuli did not differ between WDR and HT neurons, and no differences in responses of these neurons were observed between treatment groups. In animals pretreated with vehicle, WDR and HT neurons exhibited sensitization to heat after capsaicin as 


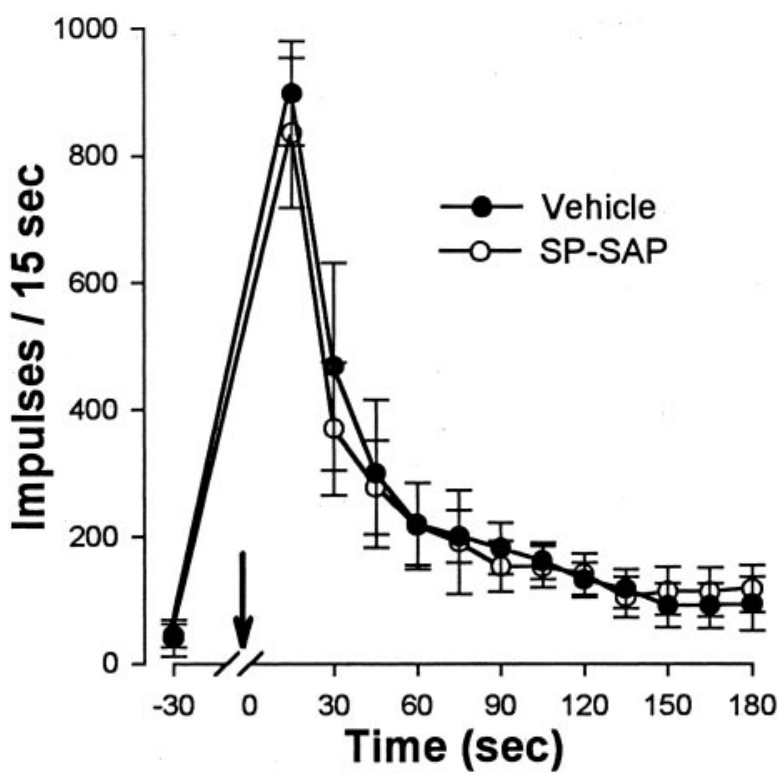

Figure 9. Neuronal discharges evoked by $100 \mu \mathrm{g}$ of capsaicin do not differ between groups pretreated with vehicle or with SP-SAP. The mean number of impulses and the temporal profile of the capsaicin-evoked responses were nearly identical for both groups. Responses shown are the mean \pm SEM number of impulses evoked during each consecutive $15 \mathrm{sec}$ interval after capsaicin. The arrow indicates the time of injection.

indicated by a mean decrease of $5.3^{\circ} \mathrm{C}$ in response threshold (from $43.9 \pm 0.9^{\circ} \mathrm{C}$ to $\left.38.6 \pm 0.6^{\circ} \mathrm{C} ; p<0.001\right)$ and increased responses to suprathreshold stimuli (Fig. 6). The mean cumulative number of impulses evoked by all heat stimuli increased from $663 \pm 96$ before capsaicin to $1297 \pm 158$ after capsaicin (96\% increase; $p<$ 0.001). A similar degree of sensitization to heat was observed for WDR and HT neurons in SAP-treated animals (Fig. 7). The mean response threshold decreased $5.7^{\circ} \mathrm{C}$ (from $44.1 \pm 0.8^{\circ} \mathrm{C}$ to $38.4 \pm 0.8^{\circ} \mathrm{C}$ after capsaicin; $p<0.001$ ), and the mean cumulative number of impulses increased from $727 \pm 180$ to $1441 \pm 277$ (98\% increase; $p<0.001)$. In contrast, sensitization to heat after capsaicin injection did not occur in SP-SAP-treated animals (Fig. 8). Mean heat thresholds were unchanged after capsaicin (43.8 \pm $0.7^{\circ} \mathrm{C}$ before capsaicin and $43.7 \pm 0.6^{\circ} \mathrm{C}$ after capsaicin), and the mean, cumulative number of impulses evoked by all heat stimuli decreased from $749 \pm 217$ before capsaicin to $397 \pm 127$ after capsaicin $(47 \%$ decrease; $p<0.01)$. The decrease in the cumulative responses to heat was attributed to a decrease in responses evoked by the higher stimulus temperatures (Fig. $8 B$ ).

Because the excitation of nociceptive neurons evoked by $10 \mu \mathrm{g}$ of capsaicin was weak in animals pretreated with SP-SAP, it was unclear whether central sensitization failed to occur because the capsaicin-evoked response was not strong enough to induce sensitization or whether there was a disruption of the mechanisms that drive central sensitization. To address this issue, we repeated the experiments above but used a capsaicin dose of $100 \mu \mathrm{g}$ to increase the capsaicin-evoked response in SP-SAP-treated animals. In vehicle-treated animals, intraplantar injection of $100 \mu \mathrm{g}$ of capsaicin produced a strong and long-lasting discharge of eight neurons (seven WDR and one HT). The mean number of impulses during the first $15 \mathrm{sec}$ after capsaicin was $898 \pm 82$ and was similar to that produced by the $10 \mu \mathrm{g}$ dose of capsaicin in control animals. A similar level of excitation was produced in 13 neurons (12 WDR and 1 HT) of animals pretreated with SP-SAP (Fig. 9).
The mean number of impulses evoked during the first $15 \mathrm{sec}$ after $100 \mu \mathrm{g}$ of capsaicin was $836 \pm 118$ and was significantly greater than the $303 \pm 50$ impulses evoked during the first $15 \mathrm{sec}$ after 10 $\mu \mathrm{g}$ of capsaicin. Thus, mean responses of nociceptive neurons evoked by $100 \mu \mathrm{g}$ of capsaicin in vehicle- and SP-SAP-treated animals were similar to responses produced by injection of $10 \mu \mathrm{g}$ of capsaicin in control animals.

Although nociceptive neurons in animals pretreated with vehicle and SP-SAP exhibited a similar degree of capsaicin-evoked excitation, sensitization did not occur in the SP-SAP group. As illustrated in Figure 10, the mean number of impulses evoked by the suprathreshold von Frey monofilament increased from $31.1 \pm$ 9 to $57.1 \pm 11.3$ (or $83 \% ; p<0.001$ ) in animals pretreated with vehicle. However, responses of neurons in SP-SAP-treated animals were unchanged after capsaicin $(30 \pm 6.8$ impulses before capsaicin and $33.8 \pm 8.8$ impulses after capsaicin). In addition, neurons in vehicle-treated animals, but not in SP-SAP-treated animals, exhibited sensitization to heat after capsaicin. In animals pretreated with vehicle, capsaicin decreased the mean heat threshold from $43.8 \pm 1.1^{\circ} \mathrm{C}$ to $39.3 \pm 0.9^{\circ} \mathrm{C}(p<0.001)$, and the mean cumulative number of impulses evoked by all heat stimuli increased from $755 \pm 228$ to $1444 \pm 204$ (an increase of 91\%; $p<$ $0.05)$. In contrast, response thresholds for heat in animals pretreated with SP-SAP remained unchanged after capsaicin $(42.3 \pm$ $1^{\circ} \mathrm{C}$ before injection and $43 \pm 1.6^{\circ} \mathrm{C}$ after injection), and the mean cumulative number of impulses evoked by all heat stimuli after capsaicin decreased from $892 \pm 244$ to $499 \pm 208$ (or $44 \% ; p<$ $0.01)$.

\section{Effect of SP-SAP on windup}

We also examined the ability of nociceptive neurons in vehicleand SP-SAP-treated animals to develop windup. Responses to consecutive electrical stimuli were obtained for 13 WDR neurons in the vehicle-treated group and $10 \mathrm{WDR}$ neurons in the SPSAP-treated group. Electrical stimulation of the RF at a frequency of $0.5 \mathrm{~Hz}$ induced a significant increase in the C-fiberevoked response of $187 \pm 21 \%(p<0.01)$ by the 12 th stimulus compared with the response evoked by the first stimulus. Windup failed to occur in animals pretreated with SP-SAP, as shown in Figure 11.

\section{DISCUSSION}

Elimination of spinal neurons that possess the SPR using SP-SAP offers the unique opportunity to determine the role of SPRexpressing neurons, as well as other neurons, in pain processing. SP-SAP induced specific degeneration of neurons expressing SPR receptors. This observation was made previously (Mantyh et al., 1997; Nichols et al., 1999) and is supported by present data. An interesting finding of the present study was the proportional change in the functional classification of spinal neurons encountered in animals pretreated with SP-SAP. The proportion of HT neurons encountered in control animals was $\sim 36 \%$, whereas only $7 \%$ of the neurons identified in SP-SAP-treated animals were HT. This suggests that SP-SAP targeted primarily HT neurons. It has been shown in cats that HT neurons possess more SPRs than WDR neurons (Ma et al., 1996, 1997), suggesting that HT neurons are more vulnerable to SP-SAP because of the greater number of SPRs on these neurons.

The absence of sensitization and windup after SP-SAP results from elimination of SPR-expressing spinal neurons within the area of intrathecal application for the following reasons. First, SPR immunoreactivity was not altered in thoracic or cervical 
MECHANICAL
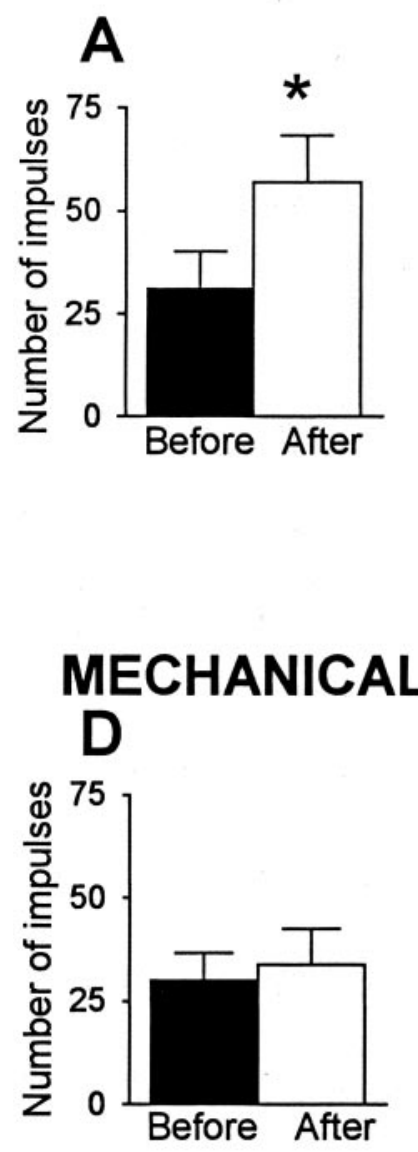

VEHICLE
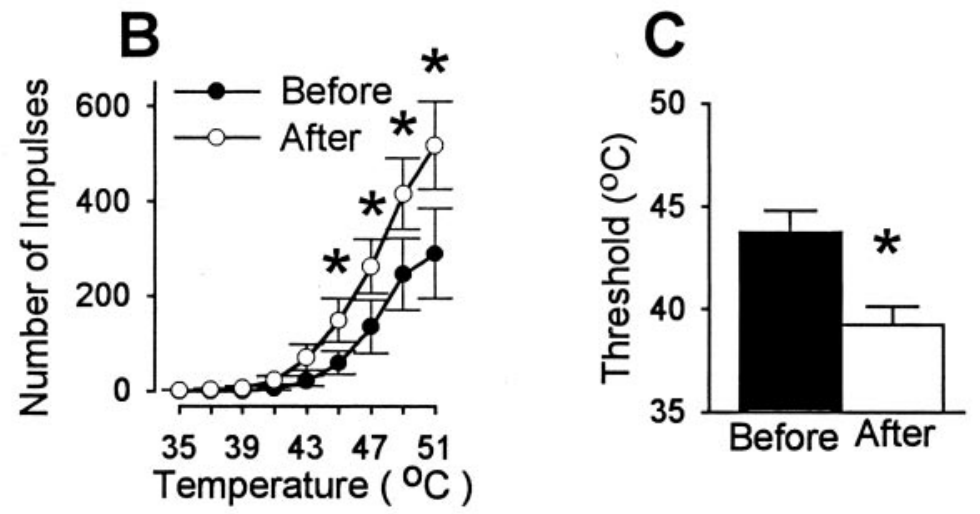
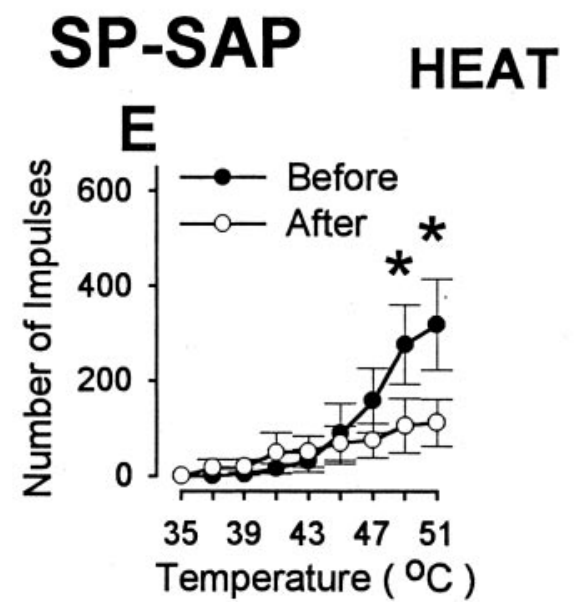

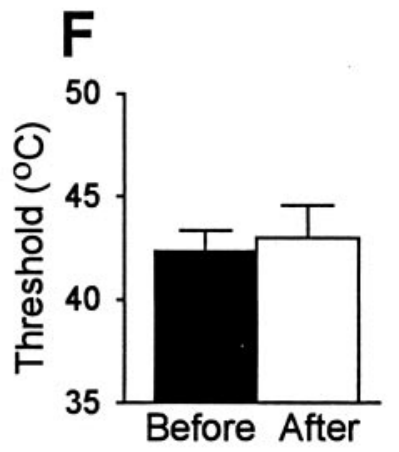

Figure 10. Capsaicin $(100 \mu \mathrm{g})$ produces sensitization after pretreatment with vehicle, but this sensitization fails to occur after SP-SAP pretreatment. Top row, Data from animals pretreated with vehicle. $A$, Mean \pm SEM number of impulses evoked by a von Frey monofilament (178 mN) before and after capsaicin. $B$, Mean \pm SEM number of impulses evoked by heat stimuli before and after capsaicin. $C$, Mean \pm SEM heat response threshold before and after capsaicin. Bottom row, Responses to mechanical $(D)$ and heat $(E, F)$ stimuli before and after capsaicin in animals pretreated with SP-SAP. *Significant difference after capsaicin.

segments after application of SP-SAP to the lumbar spinal cord, and its administration did not disrupt daily behavior patterns or locomotion (Nichols et al., 1999). These data indicate that the toxic effect of SP-SAP is localized to treated segments. Second, cell loss was not observed in the DRG (Mantyh et al., 1997; Nichols et al., 1999) after intrathecal SP-SAP, indicating that the effects of SP-SAP on central sensitization are not attributed to a presynaptic effect on primary afferent terminals.

It is particularly intriguing that a relatively small population of neurons can have such a dramatic effect on the behavioral and physiological responses of nociceptive neurons located throughout the dorsal horn. Our previous studies demonstrated that SPR-expressing neurons were necessary for the full expression of hyperalgesia after capsaicin, inflammation, and nerve injury (Mantyh et al., 1997; Nichols et al., 1999). One explanation to account for these changes is that neurons that express the SPR are the neurons that undergo central sensitization and transmit nociceptive information rostrally to account for hyperalgesia. This has been proposed to account for decreased hyperalgesia after ablation of SPR-expressing neurons using SP-diphtheria toxin conjugates (Benoliel et al., 1999). In the present study, we found that loss of $\sim 60 \%$ of SPR-expressing neurons, which constitute a small population of ascending tract neurons located primarily in the superficial dorsal horn, resulted in the inability of remaining neurons to respond vigorously to capsaicin and to exhibit sensitization and windup. This percentage of neuron loss may represent a threshold effect related to the concentration of SP-SAP, suggesting that relatively few SPR-containing neurons are required for the development of central sensitization. Remarkably, neurons located in the deep as well as the superficial dorsal horn underwent this change in their capacity to become sensitized. This indicates that SPR-expressing neurons, either directly or indirectly, modulate excitability of other superficial as well as deep dorsal horn neurons. It is possible that only SPRexpressing neurons become sensitized after capsaicin, and that the apparent sensitization of other neurons results from direct or indirect synaptic connections with these neurons. This is supported by our findings that increasing capsaicin-evoked neuronal activity in SP-SAP-treated animals to that evoked in control animals, by using a higher dose of capsaicin, failed to induce sensitization. This hypothesis can be tested by using iontophoretically applied SP and determining whether only SP-responsive 

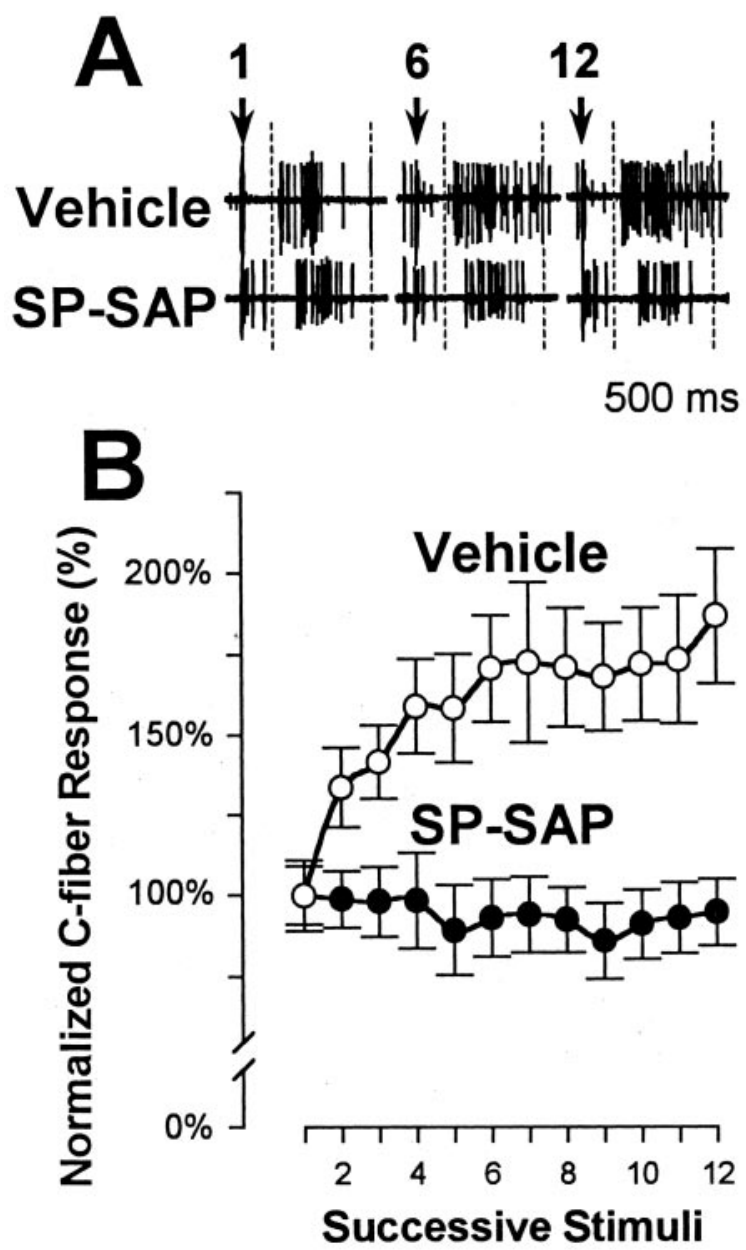

Figure 11. Nociceptive spinal neurons in SP-SAP-treated animals do not exhibit windup. $A$, Responses to electrical stimulation of a WDR neuron recorded from a vehicle- (top) and an SP-SAP (bottom)-pretreated animal. Responses are shown for the 1st, 6th, and 12th electrical stimulus. The time frame of the $\mathrm{C}$-fiber component is within the dashed line. The $\mathrm{C}$-fiber response was facilitated in the vehicle-treated animal on the 6th and 12th trial but not in the SP-SAP-treated animal. Arrows indicate time of electrical stimulation. $B$, Mean \pm SEM normalized C-fiber responses evoked by 12 successive electrical stimuli in rats pretreated with vehicle or SP-SAP. Responses were normalized to the response evoked by the first stimulus.

neurons become sensitized. The absence of central sensitization and windup recorded electromyographically from hindlimb muscles (De Felipe et al., 1998) or from single spinal neurons (Weng et al., 2001) in mice lacking the SPR also supports this concept. Regarding their role in transmission of acute pain, SPRexpressing neurons may have a minor function, because loss of these neurons in the present study, or deletion of the SPR (Weng et al., 2001), did not alter responses of nociceptive neurons to acute noxious stimuli. These findings are consistent with behavioral studies showing that antagonists of the SPR (Garces et al., 1993), knock-out of the SPR (De Felipe et al., 1998; Mansikka et al., 1999; Weng et al., 2001), or ablation of SPR-IR neurons by SP-SAP (Mantyh et al., 1997; Nichols et al., 1999) did not alter withdrawal responses to acute stimuli. Rather, it appears that neurons possessing the SPR play a pivotal role in central sensitization in that they are capable of driving the sensitization of other nociceptive neurons after injury. Unfortunately, clinical studies have shown that SPR (NK-1) antagonists were not very effective in reducing hyperalgesia (Hill, 2000; Urban and Fox, 2000). One possibility to account for this disappointing finding is that the SPR may be important for the development but not the maintenance of central sensitization (Ma and Woolf, 1995). Activation of the SPR may play a pivotal role in initiating sensitization of SPR-expressing neurons, which would influence excitability of other neurons. However, once central sensitization is developed, it is maintained by circuitry involving sensitized SPR-expressing neurons. The inability of sensitization to occur after deletion of the SPR (De Felipe et al., 1998; Weng et al., 2001) or ablation of SPR-expressing neurons by SP-SAP (Nichols et al., 1999) supports this concept.

The precise mechanisms by which the small population of SPR-expressing neurons contributes to the development of central sensitization are unclear. One possibility is that these neurons are part of a supraspinal circuit that activates descending facilitation mechanisms to increase the excitability of nociceptive dorsal horn neurons. Accumulating evidence shows that in addition to the well known descending antinociceptive pathways (Basbaum and Fields, 1978; Fields and Basbaum, 1978), other descending pathways exist that facilitate spinal nociceptive responses (Urban and Gebhart, 1999; Porreca et al., 2001; Vanderah et al., 2001a,b). Pronociceptive actions have been proposed for descending noradrenergic projections (Martin et al., 1999) and serotoninergic neurons (Calejesan et al., 1998) using spinal 5- $\mathrm{HT}_{1 \mathrm{~A}}$ (Millan and Colpaert, 1991a,b) and possibly 5-HT 3 (Ali et al., 1996) receptors. Interestingly, descending facilitation and inhibition could be produced from the rostral ventromedial medulla (RVM) depending on intensity of activation. Low and high levels of RVM stimulation correspondingly produced pronociceptive and antinociceptive effects on spinal neurons (Smith et al., 1997; Urban and Gebhart, 1997; Zhuo and Gebhart, 1997; Calejesan et al., 1998). Moreover, lesion of the RVM (Urban et al., 1996, 1999) or injection of lidocaine into the RVM (Mansikka and Pertovaara, 1997; Kauppila et al., 1998; Pertovaara, 1998) eliminated descending facilitation and inhibited certain types of hyperalgesia. Importantly, neurons in the superficial spinal laminas project to the periaqueductal gray matter (PAG) (Keay et al., 1997), a large proportion of which possesses the SPR (Todd et al., 2000), and from the PAG to RVM (Li et al., 1990; Zeng et al., 1991). Thus, activation of ascending SPR-expressing neurons may activate those structures involved in descending facilitation. Interestingly, it is likely that SPR-expressing neurons do not play a prominent role in activation of descending tonic inhibition from the RVM (Li et al., 1998), because no differences were observed in the neuronal responses evoked by mechanical and heat stimuli between SP-SAP and control animals before capsaicin. If SPR-expressing neurons contributed to tonic activation of descending inhibitory pathways, responses of spinal neurons would be expected to increase in SP-SAP-treated animals. Blockade of descending inhibitory pathways has been shown to increase the spontaneous and evoked activity of nociceptive dorsal horn neurons (Vanegas et al., 1997; Budai et al., 1998; Li et al., 1998) and to increase receptive field area (Pubols et al., 1991).

A second possible mechanism by which SPR-expressing neurons promote central sensitization is through segmental processes whereby these neurons can modulate the excitability of neighboring neurons. Central sensitization can occur through local processes and without bulbo-spinal influences, as demonstrated using an isolated rat spinal cord (Woolf, 1992; Baba et al., 1999; Nakatsuka et al., 1999). Anatomical studies have shown that many deep dorsal horn neurons possess dorsally directed dendrites that 
receive information from lamina I neurons (Honore et al., 1999; Nichols et al., 1999). Thus, activation and sensitization of SPRexpressing neurons may provide at least part of the input for other ascending tract cells. We also found that in SP-SAP-treated rats, responses to the most intense heat stimuli $\left(47-51^{\circ} \mathrm{C}\right)$ tended to decrease after capsaicin. This may be caused by the disruption of segmental neuronal circuits normally driven by SPRexpressing neurons and is supported by studies demonstrating a unique function for SP in transmission of moderate to intense pain (Cao et al., 1998; Mansikka et al., 1999).

In conclusion, dorsal horn neurons that possess the SPR play a pivotal role in the development of central sensitization and hyperalgesia. Activity of these neurons is capable of modifying response properties of remaining nociceptive neurons through either direct or indirect circuitry. Understanding the mechanisms by which SPR-expressing neurons can influence excitability of other neurons, as well as the molecular changes that occur in these cells after their activation, may identify new targets for treating chronic pain and hyperalgesia.

\section{REFERENCES}

Ali Z, Wu G, Kozlov A, Barasi S (1996) The role of 5HT3 in nociceptive processing in the rat spinal cord: results from behavioural and electrophysiological studies. Neurosci Lett 208:203-207.

Baba H, Doubell TP, Woolf CJ (1999) Peripheral inflammation facilitates $\mathrm{A} \beta$ fiber-mediated synaptic input to the substantia gelatinosa of the adult rat spinal cord. J Neurosci 19:859-867.

Basbaum AI, Fields HL (1978) Endogenous pain control mechanisms: review and hypothesis. Ann Neurol 4:451-462.

Benoliel R, Eliav E, Mannes AJ, Caudle RM, Leeman S, Iadarola MJ (1999) Actions of intrathecal diphtheria toxin-substance P fusion protein on models of persistent pain. Pain 79:243-253.

Brown JL, Liu H, Maggio JE, Vigna SR, Mantyh PW, Basbaum AI (1995) Morphological characterization of substance $P$ receptorimmunoreactive neurons in the rat spinal cord and trigeminal nucleus caudalis. J Comp Neurol 356:327-344.

Budai D, Harasawa I, Fields HL (1998) Midbrain periaqueductal gray (PAG) inhibits nociceptive inputs to sacral dorsal horn nociceptive neurons through alpha2-adrenergic receptors. J Neurophysiol 80:2244-2254.

Calejesan AA, Ch'ang MH, Zhuo M (1998) Spinal serotonergic receptors mediate facilitation of a nociceptive reflex by subcutaneous formalin injection into the hindpaw in rats. Brain Res 798:46-54.

Cao YQ, Mantyh PW, Carlson EJ, Gillespie AM, Epstein CJ, Basbaum AI (1998) Primary afferent tachykinins are required to experience moderate to intense pain. Nature 392:390-394.

De Felipe C, Herrero JF, O'Brien JA, Palmer JA, Doyle CA, Smith AJ, Laird JM, Belmonte C, Cervero F, Hunt SP (1998) Altered nociception, analgesia and aggression in mice lacking the receptor for substance P. Nature 392:394-397.

Duggan AW, Morton CR, Zhao ZQ, Hendry IA (1987) Noxious heating of the skin releases immunoreactive substance $\mathrm{P}$ in the substantia gelatinosa of the cat: a study with antibody microprobes. Brain Res 403:345-349.

Fields HL, Basbaum AI (1978) Brainstem control of spinal paintransmission neurons. Annu Rev Physiol 40:217-248.

Garces YI, Rabito SF, Minshall RD, Sagen J (1993) Lack of potent antinociceptive activity by substance P antagonist CP-96,345 in the rat spinal cord. Life Sci 52:353-360.

Hill R (2000) NK1 (substance P) receptor antagonists-why are they not analgesic in humans? Trends Pharmacol Sci 21:244-246.

Honore P, Menning PM, Rogers SD, Nichols ML, Basbaum AI, Besson JM, Mantyh PW (1999) Spinal substance P receptor expression and internalization in acute, short-term, and long-term inflammatory pain states. J Neurosci 19:7670-7678.

Kauppila T, Kontinen VK, Pertovaara A (1998) Influence of spinalization on spinal withdrawal reflex responses varies depending on the submodality of the test stimulus and the experimental pathophysiological condition in the rat. Brain Res 797:234-242.

Keay KA, Feil K, Gordon BD, Herbert H, Bandler R (1997) Spinal afferents to functionally distinct periaqueductal gray columns in the rat: an anterograde and retrograde tracing study. J Comp Neurol 385:207-229.

Li HS, Monhemius R, Simpson BA, Roberts MH (1998) Supraspinal inhibition of nociceptive dorsal horn neurones in the anaesthetized rat: tonic or dynamic? J Physiol (Lond) 506:459-469.

Li YQ, Rao ZR, Shi JW (1990) Collateral projections from the midbrain periaqueductal gray to the nucleus raphe magnus and nucleus accum- bens in the rat. A fluorescent retrograde double-labeling study. Neurosci Lett 117:285-288.

Littlewood NK, Todd AJ, Spike RC, Watt C, Shehab SA (1995) The types of neuron in spinal dorsal horn which possess neurokinin-1 receptors. Neuroscience 66:597-608.

Ma QP, Woolf CJ (1995) Involvement of neurokinin receptors in the induction but not the maintenance of mechanical allodynia in rat flexor motoneurones. J Physiol (Lond) 486:769-777.

Ma W, Ribeiro-Da-Silva A, De Koninck Y, Radhakrishnan V, Henry JL, Cuello AC (1996) Quantitative analysis of substance P-immunoreactive boutons on physiologically characterized dorsal horn neurons in the cat lumbar spinal cord. J Comp Neurol 376:45-64.

Ma W, Ribeiro-da-Silva A, De Koninck Y, Radhakrishnan V, Cuello AC, Henry JL (1997) Substance P and enkephalin immunoreactivities in axonal boutons presynaptic to physiologically identified dorsal horn neurons. An ultrastructural multiple-labeling study in the cat. Neuroscience 77:793-811.

Mannion RJ, Woolf CJ (2000) Pain mechanisms and management: a central perspective. Clin J Pain 16:S144-S156.

Mansikka H, Pertovaara A (1997) Supraspinal influence on hindlimb withdrawal thresholds and mustard oil-induced secondary allodynia in rats. Brain Res Bull 42:359-365.

Mansikka H, Shiotani M, Winchurch R, Raja SN (1999) Neurokinin-1 receptors are involved in behavioral responses to high-intensity heat stimuli and capsaicin-induced hyperalgesia in mice. Anesthesiology 90:1643-1649.

Mantyh PW, Rogers SD, Honore P, Allen BJ, Ghilardi JR, Li J, Daughters RS, Lappi DA, Wiley RG, Simone DA (1997) Inhibition of hyperalgesia by ablation of lamina I spinal neurons expressing the substance P receptor. Science 278:275-279.

Martin WJ, Gupta NK, Loo CM, Rohde DS, Basbaum AI (1999) Differential effects of neurotoxic destruction of descending noradrenergic pathways on acute and persistent nociceptive processing. Pain 80:57-65

McCarthy PW, Lawson SN (1989) Cell type and conduction velocity of rat primary sensory neurons with substance P-like immunoreactivity. Neuroscience 28:745-753.

Millan MJ (1999) The induction of pain: an integrative review. Prog Neurobiol 57:1-164.

Millan MJ, Colpaert FC (1991a) 5-hydroxytryptamine (HT)1A receptors and the tail-flick response. II. High efficacy 5-HT1A agonists attenuate morphine-induced antinociception in mice in a competitivelike manner. J Pharmacol Exp Ther 256:983-992.

Millan MJ, Colpaert FC (1991b) 5-hydroxytryptamine (HT)1A receptors and the tail-flick response. III. Structurally diverse 5-HT1A partial agonists attenuate mu- but not kappa-opioid antinociception in mice and rats. J Pharmacol Exp Ther 256:993-1001.

Moochhala SM, Sawynok J (1984) Hyperalgesia produced by intrathecal substance $\mathrm{P}$ and related peptides: desensitization and cross desensitization. Br J Pharmacol 82:381-388.

Nakatsuka T, Park JS, Kumamoto E, Tamaki T, Yoshimura M (1999) Plastic changes in sensory inputs to rat substantia gelatinosa neurons following peripheral inflammation. Pain 82:39-47.

Nichols ML, Allen BJ, Rogers SD, Ghilardi JR, Honore P, Luger NM, Finke MP, Li J, Lappi DA, Simone DA, Mantyh PW (1999) Transmission of chronic nociception by spinal neurons expressing the substance P receptor. Science 286:1558-1561.

Pertovaara A (1998) A neuronal correlate of secondary hyperalgesia in the rat spinal dorsal horn is submodality selective and facilitated by supraspinal influence. Exp Neurol 149:193-202.

Porreca F, Burgess SE, Gardell LR, Vanderah TW, Malan TP, Ossipov MH, Lappi DA, Lai J (2001) Inhibition of neuropathic pain by selective ablation of brainstem medullary cells expressing the $\mu$-opioid receptor. J Neurosci 21:5281-5288.

Pubols LM, Simone DA, Bernau NA, Atkinson JD (1991) Anesthetic blockade of the dorsolateral funiculus enhances evoked activity of spinal cord dorsal horn neurons. J Neurophysiol 66:140-152.

Radhakrishnan V, Henry JL (1991) Novel substance P antagonist, CP96,345 , blocks responses of cat spinal dorsal horn neurons to noxious cutaneous stimulation and to substance P. Neurosci Lett 132:39-43.

Schaible HG, Jarrott B, Hope PJ, Duggan AW (1990) Release of immunoreactive substance $\mathrm{P}$ in the spinal cord during development of acute arthritis in the knee joint of the cat: a study with antibody microprobes. Brain Res 529:214-223.

Simone DA, Sorkin LS, Oh U, Chung JM, Owens C, LaMotte RH, Willis WD (1991) Neurogenic hyperalgesia: central neural correlates in responses of spinothalamic tract neurons. J Neurophysiol 66:228-246.

Smith DJ, Hawranko AA, Monroe PJ, Gully D, Urban MO, Craig CR, Smith JP, Smith DL (1997) Dose-dependent pain-facilitatory and -inhibitory actions of neurotensin are revealed by SR 48692, a nonpeptide neurotensin antagonist: influence on the antinociceptive effect of morphine. J Pharmacol Exp Ther 282:899-908.

Todd AJ, McGill MM, Shehab SA (2000) Neurokinin 1 receptor expression by neurons in laminae I, III and IV of the rat spinal dorsal horn that project to the brainstem. Eur J Neurosci 12:689-700. 
Treede RD, Meyer RA, Raja SN, Campbell JN (1992) Peripheral and central mechanisms of cutaneous hyperalgesia. Prog Neurobiol 38:397-421.

Urban LA, Fox AJ (2000) NK1 receptor antagonists-are they really without effect in the pain clinic? Trends Pharmacol Sci 21:462-464.

Urban MO, Gebhart GF (1997) Characterization of biphasic modulation of spinal nociceptive transmission by neurotensin in the rat rostral ventromedial medulla. J Neurophysiol 78:1550-1562.

Urban MO, Gebhart GF (1999) Supraspinal contributions to hyperalgesia. Proc Natl Acad Sci USA 96:7687-7692.

Urban MO, Jiang MC, Gebhart GF (1996) Participation of central descending nociceptive facilitatory systems in secondary hyperalgesia produced by mustard oil. Brain Res 737:83-91.

Urban MO, Zahn PK, Gebhart GF (1999) Descending facilitatory influences from the rostral medial medulla mediate secondary, but not primary hyperalgesia in the rat. Neuroscience 90:349-352.

Vanderah TW, Ossipov MH, Lai J, Malan TP, Porreca F (2001a) Mechanisms of opioid-induced pain and antinociceptive tolerance: descending facilitation and spinal dynorphin. Pain 92:5-9.

Vanderah TW, Suenaga NM, Ossipov MH, Malan TP, Lai J, Porreca F (2001b) Tonic descending facilitation from the rostral ventromedial medulla mediates opioid-induced abnormal pain and antinociceptive tolerance. J Neurosci 21:279-286.

Vanegas H, Tortorici V, Eblen-Zajjur A, Vasquez E (1997) PAGmicroinjected dipyrone (metamizol) inhibits responses of spinal dorsal horn neurons to natural noxious stimulation in rats. Brain Res 759:171-174.

Weng HR, Mansikka H, Winchurch R, Raja SN, Dougherty PM (2001) Sensory processing in the deep spinal dorsal horn of neurokinin-1 receptor knockout mice. Anesthesiology 94:1105-1112.

Woolf CJ (1992) Excitability changes in central neurons following peripheral damage: role of central sensitization in the pathogenesis of pain. In: Hyperalgesia and allodynia (Willis WD, ed). New York: Raven.

Zeng SL, Li YQ, Rao ZR, Shi JW (1991) Projections from serotoninand substance P-like immunoreactive neurons in the midbrain periaqueductal gray onto the nucleus reticularis gigantocellularis pars alpha in the rat. Neurosci Lett 131:205-209.

Zhuo M, Gebhart GF (1997) Biphasic modulation of spinal nociceptive transmission from the medullary raphe nuclei in the rat. $\mathrm{J}$ Neurophysiol 78:746-758. 